\title{
SWEET SULFAMETHAZINE ACESULFAMATE CRYSTALS WITH IMPROVED COMPACTION PROPERTY
}

\author{
A DISSERTATION \\ SUBMITTED TO THE FACULTY OF \\ UNIVERSITY OF MINNESOTA \\ BY
}

\begin{abstract}
Sibo Liu
IN PARTIAL FULFILLMENT OF THE REQUIREMENTS

FOR THE DEGREE OF

MASTER OF SCIENCE
\end{abstract}

Changquan Calvin Sun, Advisor

July, 2019 
(C) Sibo Liu 2019 


\section{Acknowledgements}

I would like to begin with expressing my deepest appreciation to my adviser, Dr. Changquan Calvin Sun, for his inspiring guidance, unremitting assistance and support, as well as considerate care for not only lab work but everyday life. Since joining his research group, he has been my excellent mentor in my research projects, and discussing ideas thoughtfully and with insight. His contagious passion for science enabled me to pursue my research in a systematic and enthusiastic manner. The rational and thoughtful research approach and disciplined process in manuscript writing were critical in my development, which will motivate my future work. It is my great honor and pleasure to have Dr. Sun as my advisor during my journey for a master's degree in pharmaceutics at the University of Minnesota.

I am also grateful to have Dr. Timothy S. Wiedmann and Dr. Nathan Mara as my master's final examination committee members. The thoughtful opinions and constructive comments provided added clarity to dissertation. I also would like to extend my special appreciation to Dr. Timothy S. Wiedmann for his suggestions and kindness during my interview.

It's my great pleasure to be a member of Sun Lab, which is a close community just like a family. I appreciated the questions and comments provided by my lab members, as well as the discussions during the group meetings. I would like to 
extent my heartfelt gratitude to Dr. Chenguang Wang, for his guidance and assistance in my research projects and manuscript writing. My appreciation also goes to Dr. Shubhajit Paul and Dr. Manish Mishra, for their suggestions and supports in powder compaction and single crystal X-ray diffraction experiments. I would also like to thank Sun Lab members, Dr. Wei-Jhe Sun, Dr. Shao-Yu Chang, Mr. Jiangnan Dun, Ms. Shenye $\mathrm{Hu}$, Mr. Hongbo Chen, Ms. Kunlin Wang, Ms. Yiwang Guo, Mr. Ling Zhu, Mr. Zhongyang Shi and Ms. Zhengxuan Liang for a wonderful comradeship, and visiting scholars, Ms. Cosima Hirschberg, Prof. Hongliang Wen, Prof. Yuebin Ge, Prof. Wei Li and Prof. Jun Wen for informative discussions and interactions. The unforgettable days I spent with you here will always be shining in my memory and would never fade.

Finally, I would like to thank my family, for the unconditional love and support all through my life. You have provided me with a strong and durable shield that protects me from worries and scares. 


\begin{abstract}
Sulfamethazine (SMT) is a sulfonamide antibacterial drug used to treat or prevent infections in both humans and animals. However, SMT has an unfavorable taste and poor compaction behavior. To overcome these problems, a 1:1 complex with an artificial sweetener, acesulfame (Acs), was prepared and characterized. The single crystal structure suggests that the new complex, SMT-Acs, is a salt. This was confirmed by analysis of $\mathrm{C}-\mathrm{N}$ bond length and comparison to multicomponent SMT crystals with known ionization states of SMT and Fourier transformation infrared spectroscopy. The applicability of the $\Delta \mathrm{pK}_{\mathrm{a}}$ rule in multicomponent crystals of SMT is discussed. SMT-Acs exhibits better tabletability than SMT, which is attributed to its greater plasticity as shown by Heckel and Kuentz Leuenberger analysis. The greater plasticity of SMT-Acs is consistent with the presence of slip planes identified by combined energy framework and topological analysis of the crystal structure.
\end{abstract}




\section{Table of Contents}

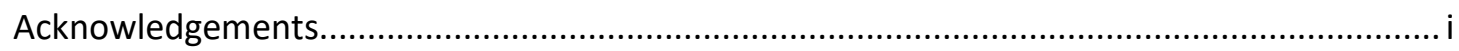

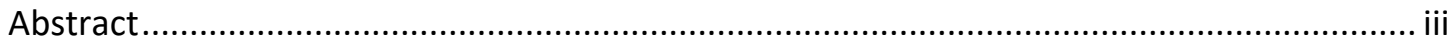

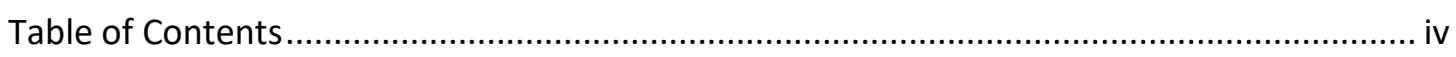

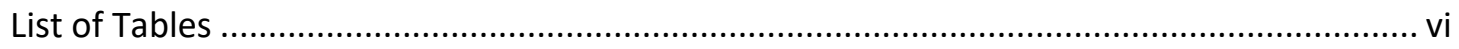

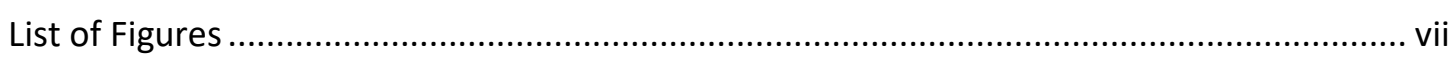

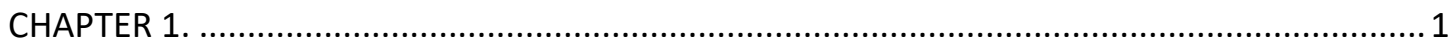

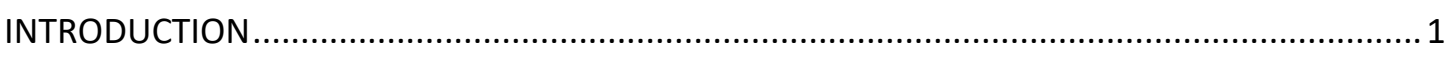

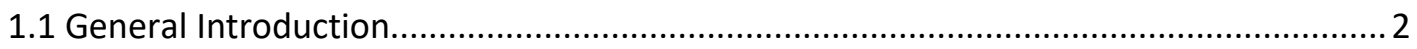

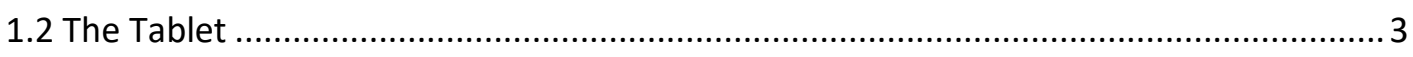

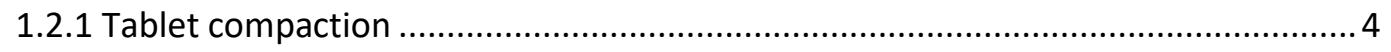

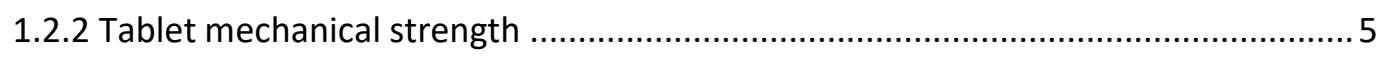

1.2.3 The bonding area - bonding strength (BABS) model......................................... 6

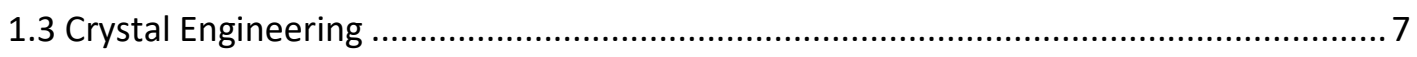

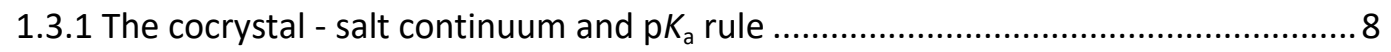

1.3.2 Impact on drug properties and performance ................................................... 9

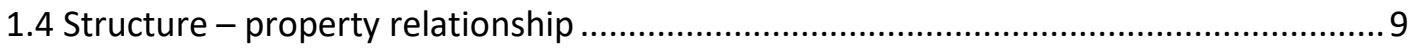

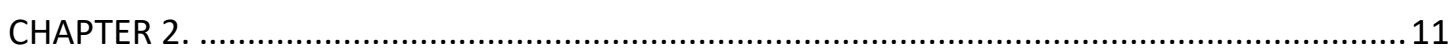

SWEET SULFAMETHAZINE ACESULFAMATE CRYSTALS WITH IMPROVED COMPACTION

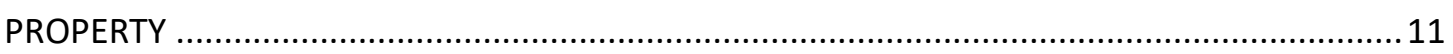

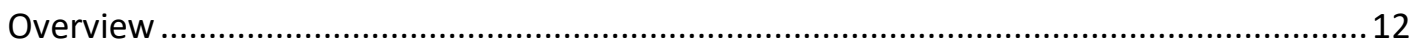

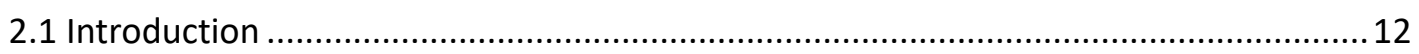

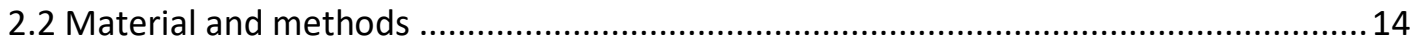

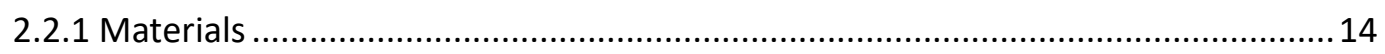

2.2.2 Preparation of single crystals .............................................................................. 14

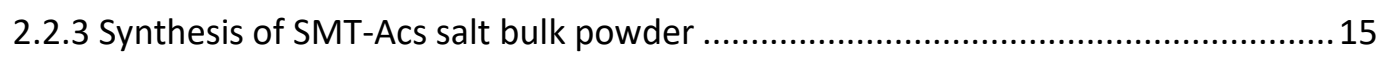

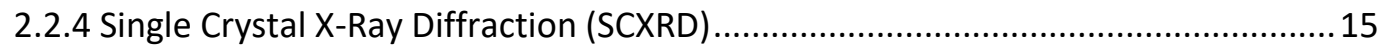




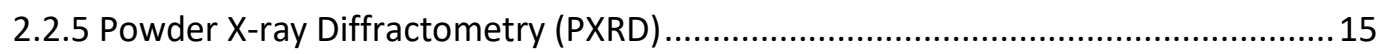

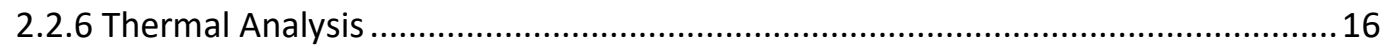

2.2.7 Fourier Transformation Infrared Spectroscopy (FT-IR) ..................................... 16

2.2.8 Dynamic Water Vapor Sorption Isotherm (DVS)............................................... 17

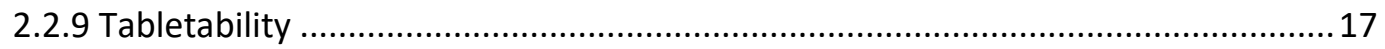

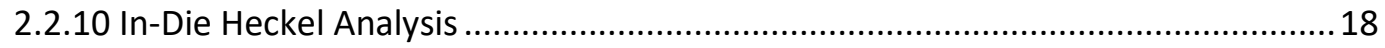

2.2.11 Out-of-Die Kuentz-Leuenberger (KL) analysis ................................................ 19

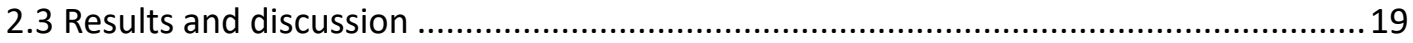

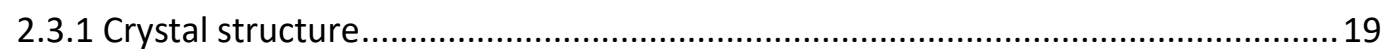

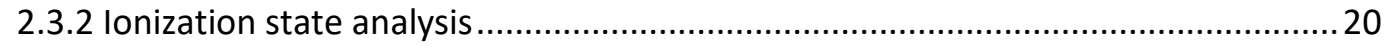

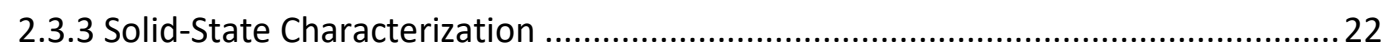

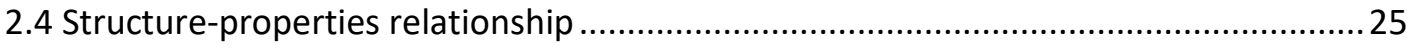

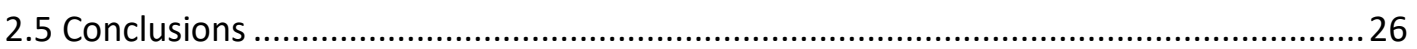

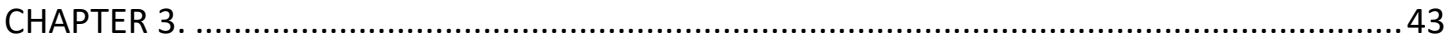

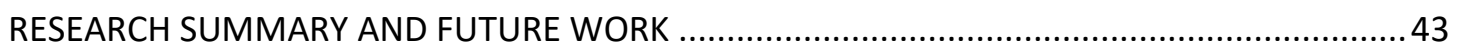

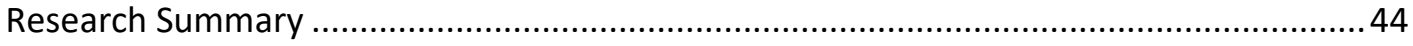

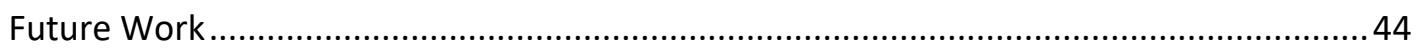

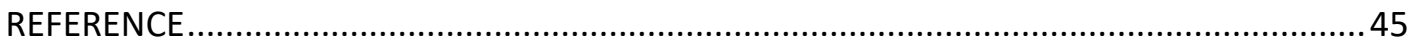




\section{List of Tables}

\section{Chapter. 2}

2.1 Crystallographic data for the SMT-Acs crystal

2.2 Hydrogen bonds in SMT-Acs crystal

2.3 Realistic interaction sites and corresponding $\Delta \mathrm{p} K_{\mathrm{a}}$ in multicomponent crystals of SMT

2.4 Plasticity parameters of SMT and SMT-Acs from in-die Heckel analysis and out-of-die KL analysis 


\section{List of Figures}

\section{Chapter. 2}

2.1 Molecular structure of (a) sulfamethazine (b) acesulfame

2.2 Crystal structure of SMT-Acs: (a) unit cell viewed along $a$-axis, (b) asymmetric unit, (c) $\mathrm{SMT}^{+}$cations formed a chain along the $b$-axis, (d) three-dimensional packing diagram.

2.3 Ionization state distribution of SMT multicomponent crystals versus $\Delta \mathrm{p} K_{\mathrm{a}}$ between interacting groups. Saccharin (blue line) forms both cocrystal and salt with SMT, while theophylline (orange line) forms cocrystal with amidine and imidine SMT simultaneously

2.4 Bond length distributions of (a) $\mathrm{C}_{1}-\mathrm{N}_{2} v s . \mathrm{C}_{1}-\mathrm{N}_{1}$ for SMT in crystal structures containing SMT, (b) $\mathrm{C}_{2}-\mathrm{N}_{3}$ vs. $\mathrm{C}_{2}-\mathrm{O}_{1}$ for Acs in known crystal structures containing Acs

2.5 IR spectra for SMT, Acs-K, and SMT-Acs. The $2636 \mathrm{~cm}^{-1}$ broad peak corresponds to $\mathrm{NH}^{+}$stretching

2.6 Calculated and experimental PXRD patterns of SMT-Acs

2.7 Thermal analysis of SMT, Acs, and SMT-Acs: (a) DSC, (b) 
HSM, and (c) TGA

2.8 Moisture sorption curves of SMT, Acs and SMT-Acs

2.9 (a) Tabletability (b) compressibility, and (c) compactability profiles of SMT and SMT-Acs. The $90 \%$ confidence band is shaded in (c)

2.10 Particle size of (a) SMT and (b) SMT-Acs

2.11 Crystal packing patterns (left) and corresponding energy framework (right) for SMT (a, b) and SMT-Acs salt (c, d) viewed along $c$ axis. The thickness of each cylinder (in blue) represents the relative strength of interaction 
CHAPTER 1.

INTRODUCTION 


\subsection{General Introduction}

The tablet is the most commonly used dosage form for oral drug delivery. ${ }^{1}$ It has advantages over other dosage forms, including 1) accurate dose; 2) generally better chemical, physical and microbiological stability; 3) lower cost for manufacturing and distribution; 4) ease of administration; and 5) better patient compliance. ${ }^{2-4}$ In order to develop a successful tablet product, several quality standards have to be met to ensure the efficacy and safety of the drug product. Adequate tablet mechanical strength is one of the key factors that needs to be considered. ${ }^{5}$

Crystal engineering is the rational design of fundamental molecular solids. ${ }^{6}$ It is of both fundamental and practical interest to scientists in multiple fields, such as chemistry, material science, and pharmaceutical sciences. ${ }^{7}$ Specifically in pharmaceutical sciences, crystal engineering has gradually become a successful design strategy to obtain novel multicomponent complexes of active pharmaceutical ingredients (APIs) with desired physicochemical properties but without affecting their pharmacological performances. ${ }^{8}$ Numerous recent examples have amply shown the applicability of crystal engineering in improving mechanical properties, stability, solubility, and bioavailability of APIs. ${ }^{9-12}$

Understanding the relationship between crystal packing and the mechanical properties of the crystals is of interest in the fields of solid-state chemistry and crystal engineering. ${ }^{9}, 10,12,13$ In pharmaceutical sciences, the structure-property relationship provides a foundation for understanding different tableting behaviors of 
APIs. ${ }^{12,14-16}$ Pursuit of greater applicability of this relationship is now aided by computational tools, such as energy framework calculation and topology analysis, which can bring the goal of accurately predicting the compaction behaviors of crystals closer. $^{17,18}$

\subsection{The Tablet}

The tablet originated in mid 1800s and has been extensively investigated and widely used for many APIs. ${ }^{19}$ Based on the intended clinical use, several types of tablets have been designed, including: 1) immediate release; 2) sustained/controlled release; 3) delayed release; 4) buccal and sublingual; 5) chewable; 6) effervescent, and 7) orally disintegrating tablets. ${ }^{2} \quad$ A tablet product may belong to more than one of the specific types.

Tablets exhibit advantages in both manufacturing and administration. With respect to manufacturing, tablets generally exhibit better chemical, physical and microbiological stability, lower cost for manufacturing and distribution, as well as more accurate dose. ${ }^{2-4}$ The ease of administration is another major benefit that leads to better patient compliance and therapeutic outcomes. ${ }^{2-4}$

In order to develop a successful tablet product, several quality standards have to be met to ensure efficacy and safety. Adequate mechanical strength is essential as a tablet cannot exist in its absence..$^{5}$ Parameters, such as particle size and shape, surface texture, plasticity, brittleness, viscoelasticity, and moisture content, can all 
influence the tableting behavior of APIs.

\subsubsection{Tablet compaction}

Tablets are typically prepared with a tablet press, where the volume of a powder is reduced under a compaction force. ${ }^{20}$ The compaction process, which takes place in a tooling set (a die and two punches), can be divided into four phases involving the specific mechanisms of 1) die filling and particle slippage, 2) compression, 3) decompression and 4) ejection. ${ }^{21,22}$ When the punches come in contact with the powder in the die, a low pressure is applied and particles undergo rearrangement through sliding and rotation. This results in a more densely pack powder bed in the die. Displacement of trapped air in bulk powder occurs, and the powder bed porosity decreases. At a critical porosity, the loose powder transitions into a rigid body, ${ }^{22}$ marking the initiation of the compression stage. The continuously increasing compaction pressure and volume reduction of the powder causes deformation of the particles, including particle fracture, elastic deformation, and plastic deformation. Elastic deformation is temporary and reversible, but plastic deformation is permanent and irreversible. ${ }^{21}$ The compaction pressure reaches the maximum at the end of the compression phase. The decompression phase, where the punches move away from each other, ensures the stress is reduced to zero. In the ejection phase, the compact is pushed out of the die. Tablets gain their mechanical strength from the compaction process, and the mechanical strength is governed by the total area of contact (bonding area) and the strength of particle interactions 
(bonding strength). ${ }^{21}$ This bonding area - bonding strength (BABS) interplay model will be further discussed in 1.2.3.

\subsubsection{Tablet mechanical strength}

The mechanical strength of tablets obtained is dependent upon a number of factors, e.g., physicochemical, particulate and mechanical properties of the bulk powder, as well as the conditions used for powder compression, such as compaction pressure and speed. $^{23,24}$ Tablet mechanical strength can be quantified by a number of standard measurements, including breaking force ${ }^{25}$, tensile strength $^{21}$, fracture toughness ${ }^{25}$, indentation hardness, ${ }^{26}$ and tablet friability ${ }^{27}$.

Tablet tensile strength is one of the most commonly used parameter for quantifying mechanical strength. ${ }^{28}$ Unlike breaking force, tablet size and geometry are taken into account in the determination of tensile strength. The tensile strength $(\sigma)$ of a cylindrical tablet can be obtained from the diametral compression test ${ }^{29}$, using eqn. 1

$$
\sigma=\frac{2 F}{\pi D h}
$$

Where $F$ is the breaking force, $D$ is tablet diameter, and $h$ is tablet thickness.

Adequate tablet tensile strength is required for successful tablet product development and manufacturing. On one hand, sufficient strength is needed for tablets to maintain their integrity during packaging, shipping and handling. Weak tablets may lead to problems, including unacceptable friability, reduced dose and a lack of 
pharmaceutical elegance (good quality in tablet size, shape and color). On the other hand, very strong tablets are difficult to break, as may be needed for patients with difficulty in swallowing. Furthermore, it can also result in slower rate of tablet disintegration and drug dissolution. ${ }^{21}$

\subsubsection{The bonding area - bonding strength (BABS) model}

Tabletability is the ability of a material to form tablets with adequate mechanical strength by powder compaction, which is of critical importance to successful tablet product manufacturing. ${ }^{21}$ Tabletability profiles can be obtained by plotting tablet tensile strength as a funtion compaction pressure. To explain the diverse tableting behaviors of pharmaceutical powders, ${ }^{15,}{ }^{30-37}$ a theoretical framework has been developed.

The BABS model is a qualitative model based on the concept of interparticulate boding area (BA) and boding strength (BS). ${ }^{21}$ For molecular solids, van der Waals interactions as well as hydrogen bonding are primariy responsible for BS. During the consolidation process, the powder undergoes particle rearrangement, slippage and deformation, resulting in formation of BA. BA varies with mechanical and particle properties (e.g., size and shape). The various combinations of BA and BS lead to the diverse tabletability behaviors of pharmaceutical powders, i.e., tabletability is the result of the interplay between BA and BS. A clear understanding of the contributions of BA and BS to tensile strength can guide effective formulation and process development to overcome problems due to low tabletability. 


\subsection{Crystal Engineering}

Crystal engineering is the rational design of fundamental molecular solids. ${ }^{6}$ It is of both fundamental and practical interest to researchers in multiple fields such as chemistry, material science, and pharmaceutical sciences. ${ }^{7}$ Today, this subject is actively pursued by at least 150 independent research groups worldwide, covering topics such as 1) intermolecular interactions; 2) packing modes, in the context of these interactions and with the aim of defining a design strategy; and 3) crystal structure - properties relationship and their applications to improve properties through crystal structure modifications. ${ }^{7}$

In pharmaceutical sciences, the crystal engineering approach has progressed to become a successful designing strategy to obtain novel multicomponent complexes of the APIs exhibiting desired physicochemical properties without affecting their pharmacological performances. ${ }^{8}$ Numerous examples in recent times have shown its application in attaining desirable mechanical and physicochemical properties, such as stability, solubility, and bioavailability. ${ }^{9-12}$ In this line of research, it is of fundamental importance to solve the crystal structure of the API, which facilitates the understanding of the structure - property relationship. These information augments the Quality by Design (QbD) objective (a systematic approach to development that begins with predefined objectives and emphasizes product and process understanding and process control, based on sound science and quality risk management) of pharmaceuticals in solid state. ${ }^{38}$ 


\subsubsection{The cocrystal - salt continuum and $\mathrm{p} K_{\mathrm{a}}$ rule}

Both cocrystals and salts have been used to improve pharmaceutical properties of APIs. ${ }^{11,39-41}$ However, cocrystals are not regarded as new pharmaceutical APIs whereas salts are. This means that a complete set of characterization data is required for FDA approval of pharmaceutical products containing different salts. ${ }^{42}$ This regulatory distinction makes it important to identify the ionization state of each new multicomponent complex intended for further pharmaceutical development.

The criterion that distinguishes a cocrystal drug from a salt is proton transfer. In multicomponent crystal systems, the position of the proton between the two components can be continuous based on their chemical nature, ranging from covalently bonded to the donor molecule to covalently bonded to the acceptor molecule. $^{43,44}$ However, sometimes, it is difficult to apply this seemingly simple criterion to identify a cocrystal or salt, because of several phenomena: 1) partial proton transfer ${ }^{45}$; 2) position shift of a proton with temperature between the same pair of acid and base ${ }^{46}$; 3) the extent of proton transfer depends on the packing patterns of molecules in different polymorphs and hydrates ${ }^{47}$.

The empirical $\Delta \mathrm{p} K_{\mathrm{a}}$ rule, which was developed on the basis of an analysis of 6465 crystalline complexes, has been used to predict the ionization state of crystalline complexes. $^{48,49}$ A larger $\Delta \mathrm{p} K_{\mathrm{a}}$ is correlated with a higher tendency of proton transfer. Generally, when the $\Delta \mathrm{p} K_{\mathrm{a}}\left(=\mathrm{p} K_{\mathrm{a} \text { [base] }}-\mathrm{p} K_{\mathrm{a} \text { [acid] }]}\right)$ is greater than 3 , proton transfer is highly likely to occur. ${ }^{49}$ When $\Delta \mathrm{p} K_{\mathrm{a}}<0$, proton transfer is unlikely and 
cocrystal would be expected. In the cases of $\Delta \mathrm{p} K_{\mathrm{a}}$ between 0 and 3 , either salt or cocrystal could form. ${ }^{43}$ However, the U.S. FDA proposed $\Delta \mathrm{p} K_{\mathrm{a}}=1$ as the boundary between cocrystals and salts, i.e., when $\Delta \mathrm{p} K_{\mathrm{a}}>1$, substantial proton transfer is likely to occur, resulting in salt formation; and when $\Delta \mathrm{p} K_{\mathrm{a}}<1$, cocrystals are expected to be obtained. $^{42}$

\subsubsection{Impact on drug properties and performance}

Each new multicomponent complex of any drug is expected to exhibit a distinct set of properties because of the unique structure. ${ }^{50}$ Thus, forming multicomponent complex crystals is an effective strategy for improving manufacturability and clinical performance of drug products. Demonstrated advantages of this strategy include: 1) higher solubility, dissolution rate, and bioavailability; ${ }^{.54}$ 2) greater physical and chemical stability; ${ }^{55-57}$ 3) better mechanical properties; ${ }^{11,12,58}$ and 4) improved taste profiles. ${ }^{59-61}$

\subsection{Structure - property relationship}

Understanding the relationship between crystal packing and the mechanical properties of the crystals is of interest to researchers in the fields of solid - state chemistry and crystal engineering. ${ }^{9}, 10,12,13$ For example, such structure - property relationships help explain the different tableting behavior of the material. ${ }^{12,14-16}$ In addition, computational methods, such as energy framework calculation and topology analysis, can be used to further gain insight and possibly predict the compaction behavior of 
different crystals. ${ }^{17,18}$ Acetaminophen is a good example of the efforts in developing the structure - property relationship. The orthorhombic form II was initially observed to exhibit greater tabletability compared with the monoclinic form I. $^{62}$ Later, an analysis of the crystal structures gave clues to their distinct tableting behavior: 1) pleated sheets along $\mathrm{b}$ - axis for form $\mathrm{I}$, resulting in relatively stiff structure and poor compaction behavior, and 2) parallel hydrogen - bonded sheets along $\mathrm{c}-$ axis for form II, serving as slip planes to facilitate plastic deformation. ${ }^{63}$ More recently, energy framework calculations showed that form II molecule has lower intermolecular interaction energy between neighboring sheets $\left(-106 \mathrm{~kJ} / \mathrm{mol}^{-1}\right)$ compared with a form I molecule $\left(-143 \mathrm{~kJ} / \mathrm{mol}^{-1}\right)$, indicating easier slide between sheets for form II than form I. This explains the greater plasticity and tabletability of form II. ${ }^{64}$ 


\section{CHAPTER 2.}

SWEET SULFAMETHAZINE ACESULFAMATE

\section{CRYSTALS WITH IMPROVED COMPACTION}

\section{PROPERTY}




\section{Overview}

Sulfamethazine (SMT) is a sulfonamide antibacterial drug used to treat or prevent infections in both humans and animals. However, SMT exhibits unfavorable taste and poor compaction behavior. To overcome these problems, a 1:1 complex with an artificial sweetener, acesulfame (Acs), was prepared and characterized. The single crystal structure suggested that the new complex, SMT-Acs, is a salt. This was confirmed by an analysis of $\mathrm{C}-\mathrm{N}$ bond length in comparison to those of multicomponent SMT crystals with known ionization states of SMT and Fourier transformation infrared spectroscopy. The applicability of the $\Delta \mathrm{pK}_{\mathrm{a}}$ rule in multicomponent crystals of SMT was discussed. SMT-Acs exhibits better tabletability than SMT, which is attributed to its greater plasticity as shown by Heckel and Kuentz - Leuenberger analysis. The greater plasticity of SMT-Acs is consistent with the presence of slip planes identified by combined energy framework and topological analysis of the crystal structure.

\subsection{Introduction}


Crystal engineering, "the rational design of functional molecular solids", is of interest in multiple research fields, including pharmaceutical sciences. ${ }^{1,2}$ Numerous examples have shown the ability of attaining desirable physicochemical and mechanical properties (i.e., stability, solubility and bioavailability) of active pharmaceutical ingredients (APIs). ${ }^{3-6}$ Salt formation is an effective crystal engineering approach, where charge assisted intermolecular interactions play an important role in directing molecule packing in crystals. Hence, salt formation has been routinely applied to improve pharmaceutical properties of APIs. ${ }^{7-9}$

Sulfamethazine (SMT, Scheme 2.1a) is a sulfonamide antibacterial drug, which is used to treat or prevent infections in both humans and animals, with a broad spectrum of activity against gram-positive bacteria, gram-negative bacteria, and some protozoa. $^{10,11}$ SMT can exist in two neutral tautomers, amidine ${ }^{11-23}$ and imidine, ${ }^{11,17,}$ 24 cation (protonation of the $-\mathrm{NH}_{2}$ group, $\mathrm{p} K_{\mathrm{a}, 1}=2.65$ ), ${ }^{24-26}$ and anion (deprotonation of the sulfonamide - $\mathrm{NH}$ - group, $\left.\mathrm{p} K_{\mathrm{a}, 2}=7.65\right) .{ }^{16} \quad$ Correspondingly, various organic salts and pharmaceutical cocrystals of SMT were prepared and characterized with a focus on crystal structures and solid - state properties, except for compaction properties. Taste masking and compaction property enhancement of SMT are desired for developing high quality oral tablet products. ${ }^{27}$

Acesulfame (Acs, Scheme 2.1b), a relatively strong acid $\left(\mathrm{p} K_{\mathrm{a}}=2.0\right)$, is a calorie-free sugar substitute that is 200 times sweeter than sucrose. ${ }^{28}$ Because of its safety profile, ${ }^{29}$ Acs is a good candidate for masking the bitterness of SMT through forming a crystalline complex, as demonstrated in other drugs. ${ }^{30,31}$ The multiple 
functional groups (amide and sulfonyl amide) of Acs allows interaction with SMT hydrogen donating groups of amine $\left(-\mathrm{NH}_{2}\right)$ and sulfonamide (-NH-) and accepting groups of sulfoxy -O-, amine $-\mathrm{N}-$, and pyrimidine $-\mathrm{N}-.^{11,32}$ In this work, we investigated the possibility of forming a sweet SMT-Acs complex to improve the poor mechanical properties and taste of SMT.

\subsection{Material and methods}

\subsubsection{Materials}

Sulfamethazine (Sigma-Aldrich, St. Louis, MO), acesulfame potassium (Tokyo Chemical Industry co., Ltd., Japan), and acetonitrile (Sigma-Aldrich, St. Louis, MO) were used as received. Acs free acid was prepared from acesulfame potassium using a reported method. ${ }^{32}$

\subsubsection{Preparation of single crystals}

Equimolar SMT (556.7 mg, $2 \mathrm{mmoL}$ ) and Acs (326.3 mg, $2 \mathrm{mmoL}$ ) were suspended in $10 \mathrm{~mL}$ of acetonitrile. The suspension was stirred with a magnetic stirring bar for $24 \mathrm{~h}$ at room temperature. After $24 \mathrm{~h}$, the suspension was filtered through filter paper with a Brinell funnel, and the filtrate was collected and passed through a 0.22 mm PTFE syringe filter membrane into a vial. The vial was left open in a fume hood to allow solvent evaporation. Crystals suitable for single crystal X-ray diffraction study were harvested within one week. 


\subsubsection{Synthesis of SMT-Acs salt bulk powder}

Bulk powders of SMT-Acs salt for compaction study were prepared by suspending SMT (5.57 g, $20 \mathrm{mmoL})$ and Acs $(3.26 \mathrm{~g}, 20 \mathrm{mmoL})$ in $30 \mathrm{~mL}$ of acetonitrile and stirred for $24 \mathrm{~h}$ at room temperature. After $24 \mathrm{~h}$, the solid phase was isolated by filtration using a Brinell funnel, and the dried at room temperature overnight.

\subsubsection{Single Crystal X-Ray Diffraction (SCXRD)}

SCXRD was conducted on a Bruker-AXS Venture Photon-II diffractometer (Bruker AXS Inc., Madison, Wisconsin), with a Photon-II (CMOS) detector. Data was collected at $100 \mathrm{~K}$ using $\mathrm{Mo} \mathrm{K} \alpha$ radiation (graphite monochromator). Various software packages from Bruker, including APEX3, SADABS, and SAINT, were used for data analysis. The structure was solved using SHELXT 2014 program and

refined using SHELXL 2018 program. ${ }^{33,34}$ The space group $\mathrm{P} 2{ }_{1} / \mathrm{n}$ was determined based on systematic absences and intensity statistics. A direct-methods solution was calculated to provide most non-hydrogen atoms from the E-map. Full-matrix least-squares/difference Fourier cycles were performed to locate the remaining non-hydrogen atoms. All non-hydrogen atoms were refined with anisotropic displacement parameters. All hydrogen atoms were placed in ideal positions and refined as riding atoms with relative isotropic displacement parameters.

\subsubsection{Powder X-ray Diffractometry (PXRD)}

PXRD experiments were performed on a powder X-ray diffractometer (PANalytical 
X'pert pro, Westborough, MA), using Cu K $\alpha$ radiation (1.54056 ̊̊). Samples were scanned with a step size of $0.02^{\circ}$ and $1 \mathrm{~s} / \mathrm{step}$ dwell time from 5 to $35^{\circ}$ two theta. The tube voltage and amperage were $45 \mathrm{kV}$ and $40 \mathrm{~mA}$, respectively.

\subsubsection{Thermal Analysis}

Hot stage microscopy (HSM) was carried out using a polarized light microscopy (Eclipse e200; Nikon, Tokyo, Japan), fitted with a hot stage. Images were captured by a DS-Fi1 microscope digital camera. Crystals were heated at a rate of $5{ }^{\circ} \mathrm{C} / \mathrm{min}$ with a temperature controller (Linksys 32; V.2.2.0, Linkam Scientific Instruments, Ltd., Waterfield, UK).

The thermal properties collected on a differential scanning calorimeter (DSC) (Q1000, TA Instruments, New Castle, DE, USA). Powder samples (2 4 mg) were hermetically sealed in aluminum pans and heated with a heating rate of $10{ }^{\circ} \mathrm{C} / \mathrm{min}$ under continuous dry nitrogen purge at a flow rate of $25 \mathrm{~mL} / \mathrm{min}$. Thermal gravimetric analysis (TGA) data were collected using a thermogravimetry analyzer (Model Q500, TA Instruments, New Castle, DE, USA). Powder samples (3 5mg) were loaded in open aluminum pans, and heated from room temperature up to $300{ }^{\circ} \mathrm{C}$ at $10{ }^{\circ} \mathrm{C} / \mathrm{min}$ under a continuous dry nitrogen purge at $60 \mathrm{~mL} / \mathrm{min}$.

\subsubsection{Fourier Transformation Infrared Spectroscopy (FT-IR)}

FT-IR spectra of all solid samples were obtained using a high resolution FT-IR spectrometer (VERTEX 70, Bruker Optics Inc., Billerica, MA. USA). A total of 32 
scans for each sample were collected at $4 \mathrm{~cm}^{-1}$ resolution, and an averaged spectrum ranged from $4000-600 \mathrm{~cm}^{-1}$ was reported. The spectra were processed using OPUS software (v5.5, Bruker Optics Inc., Billerica, MA, USA).

\subsubsection{Dynamic Water Vapor Sorption Isotherm (DVS)}

Water sorption isotherms were determined at $25{ }^{\circ} \mathrm{C}$ on an automated vapor sorption analyzer (DVS 1000, Surface Measurement Systems Ltd., Alperton, Middlesex, UK), with continuous $50 \mathrm{~mL} / \mathrm{min}$ nitrogen flow. The $\mathrm{RH}$ values were increased from $0 \%$ to $95 \%$ using a step size of $5 \%$. At each step, the sample was equilibrated until one of the two criteria was met, $\mathrm{dm} / \mathrm{dt} \leq 0.003 \%$ or $6 \mathrm{~h}$ equilibration period.

\subsubsection{Tabletability}

Powder compaction studies were conducted on a material testing machine (model 1485; Zwick/ Roell, Ulm, Germany) at $4 \mathrm{~mm} / \mathrm{min}$ speed. To minimize the effect of particle size, powder samples were ground in a mortar with a pestle and passed through a \#60 mesh $(\leq 250 \mu \mathrm{m})$ sieve before compaction. Comparable particle sizes of SMT and SMT-Acs were confirmed by polarized light microscopy. Compaction was carried out over the pressure range of $20-320 \mathrm{MPa}$ using a die and flat-faced round punches ( $8 \mathrm{~mm}$ diameter). A suspension of magnesium stearate in ethanol $(5 \%$ w/v) was applied onto the punch tips and die wall using a brush, and then dried by a fan prior to filling the die with powder. Tablets were left in sealed glass vials at room temperature for at least $24 \mathrm{~h}$ to allow relaxation. The diametrical breaking 
force was determined on a texture analyzer (TA-XT2i; Texture Technologies Corporation, Scarsdale, New York). Tablet tensile strength $(\sigma)$ was calculated using eqn. $1^{35}$

$$
\sigma=\frac{2 F}{\pi D h}
$$

Where $F$ is the breaking force, $D$ is tablet diameter, and $h$ is tablet thickness.

True density of powder samples was measured by helium pycnometry (Quantachrome Instruments, ultrapycnometer 1000e, Boynton Beach, Florida). Samples (1 2g) were accurately weighed and placed into a sample cell. Measurements were repeated to a maximum of 100 or a $<0.005 \%$ coefficient of variation of five consecutive measurements was obtained. The mean of the last five measurements was reported as the true density of the sample.

\subsubsection{In-Die Heckel Analysis}

Three tablets (about $200 \mathrm{mg}$ ) were prepared at peak compaction pressures of 280, 300 and $320 \mathrm{MPa}$ at $4 \mathrm{~mm} / \mathrm{min}$ speed using a material testing machine (model 1485; Zwick/ Roell, Ulm, Germany). The force and nominal strain were exported for calculating pressure and porosity $(\varepsilon)$, which were analyzed using the Heckel equation, ${ }^{36}$ eqn. 2

$$
-\ln (\varepsilon)=K P+A
$$

Where $P$ is the compaction pressure applied, the slope $K$ and y-axis intercept $A$ are calculated using the linear portion of the Heckel plot. The mean yield pressure $\left(P_{\mathrm{y}}\right)$, which is the reciprocal of $K$, is a plasticity parameter of the powder. A lower $P_{y}$ 
value suggests higher powder plasticity.

\subsubsection{Out-of-Die Kuentz-Leuenberger (KL) analysis}

The out-of-die pressure - porosity data were analyzed using the Kuentz-Leuenberger (KL) method (Eqn. 3). ${ }^{37}$

$$
P=\frac{1}{C}\left[\varepsilon-\varepsilon_{c}-\varepsilon_{c} \ln \left(\frac{\varepsilon}{\varepsilon_{c}}\right)\right]
$$

Here, the parameter $1 / C$ is another parameter for quantifying material plasticity. Higher plasticity is indicated by a lower $1 / C$ value. The $\mathrm{KL}$ analysis is superior to Heckel analysis in analyzing compressibility data, because the former uses the entire set of data whereas the latter only uses data that appears linear over a narrower range of compaction pressure. ${ }^{38} P$ is the compaction pressure applied, $\varepsilon$ is the porosity of the powder, and the critical powder porosity, $\varepsilon_{c}$, is a parameter that describes the porosity at which the powder starts to gain rigidity or strength. ${ }^{37}$

\subsection{Results and discussion}

\subsubsection{Crystal structure}

SMT-Acs complex (CCDC: 1821691) crystallizes in the monoclinic $\mathrm{P} 21 / \mathrm{n}$ space group with four asymmetric units in unit cell $(Z=4$, Figure 2.2a). Each asymmetric unit contains one $\mathrm{SMT}^{+}$cation and one $\mathrm{Acs}^{-}$anion $\left(Z^{\prime}=1\right)$. Key crystallographic parameters are summarized in Table 2.1, and hydrogen bonds are shown in Table 2.2. Proton transfer occurs between SMT $\mathrm{N}_{2}$ site and Acs sulfonyl amide - NH- group. $\mathrm{SMT}^{+}$cation and $\mathrm{Acs}^{-}$anion are connected through two hydrogen bonds, namely, 
$\mathrm{N}_{1}-\mathrm{H}^{\cdots} \mathrm{N}_{-3}$ and $\mathrm{N}_{2}{ }^{+}-\mathrm{H}^{\cdots} \mathrm{O}_{1}=\mathrm{C}_{2}$ (Figure 2.2b). Each $\mathrm{SMT}^{+}$cation is connected to four more $\mathrm{SMT}^{+}$through $\mathrm{N}-\mathrm{H}^{\cdots} \mathrm{O}=\mathrm{S}(2.995 \AA)$ and one Acs ${ }^{-}$through the above mentioned $\mathrm{N}_{1}-\mathrm{H}^{\cdots} \mathrm{N}_{-3}(2.796 \AA)$ and $\mathrm{N}_{2}{ }^{+}-\mathrm{H}^{\cdots} \mathrm{O}_{1}=\mathrm{C}_{2},(2.627 \AA)$ hydrogen bonds, forming a $\mathrm{R}_{2}^{2}(8)$ heterosynthon (Figure 2.2b). The Acs ${ }^{-}$also connects to another $\mathrm{SMT}^{+}$through $\mathrm{N}-\mathrm{H}^{\cdots} \mathrm{O}=\mathrm{C}(3.015 \AA) . \quad \mathrm{SMT}^{+}$molecules, linked by $\mathrm{N}-\mathrm{H} \ldots \mathrm{O}=\mathrm{S}$ with bond length of $2.995 \AA$, form a zigzag chain along b-axis (Figure 2.2c). The three-dimensional packing pattern of SMT-Acs is shown in Figure 2.2d.

\subsubsection{Ionization state analysis}

\subsubsection{1 $\Delta \mathrm{p} K_{\mathrm{a}}$ analysis}

An empirical $\Delta \mathrm{p} K_{\mathrm{a}}$ rule has been proposed to predict the ionization state of crystalline complexes, which have been tested in 6465 crystalline complexes. $^{39,40}$ Generally, when the $\Delta \mathrm{p} K_{\mathrm{a}}\left(=\mathrm{p} K_{\mathrm{a} \text { [base] }}-\mathrm{p} K_{\mathrm{a} \text { [acid] }}\right)$ is greater than 3, proton transfer is highly likely to occur since a larger $\Delta \mathrm{p} K_{\mathrm{a}}$ suggests higher tendency of proton transfer. ${ }^{40}$ When $\Delta \mathrm{p} K_{\mathrm{a}}<0$, proton transfer is unlikely and a cocrystal would be expected. In the cases of $\Delta \mathrm{p} K_{\mathrm{a}}$ between 0 and 3, either salt or cocrystal could form. ${ }^{41}$ On the other hand, the U.S. FDA proposed $\Delta \mathrm{p} K_{\mathrm{a}}=1$ as the boundary between cocrystals and salts, i.e., when $\Delta \mathrm{p} K_{\mathrm{a}}>1$, substantial proton transfer is likely to occur, resulting in salt formation; and when $\Delta \mathrm{p} K_{\mathrm{a}}<1$, cocrystals are expected to be obtained. ${ }^{42}$. A search of CSD returned a total of 32 multicomponent crystals of SMT, including 26 cocrystals and 6 salts. $^{43}$ Out of the 26 cocrystals, SMT can be present in the form of 
amidine (19) or imidine (6), with one crystal contains both amidine and imidine forms. Out of the 6 salts, 4 are SMT cations and 2 are anions. However, the application of the $\Delta \mathrm{p} K_{\mathrm{a}}$ rule in SMT multicomponent crystals requires caution, since SMT can exist in different molecular forms (amidine, imidine, cation, and anion) with different $\mathrm{p} K_{\mathrm{a}} \mathrm{s}$. The correct calculation of $\Delta \mathrm{p} K_{\mathrm{a}}$ should consider functional groups that are directly involved in the interacting hydrogen/proton donating and accepting groups. The simple use of SMT amine $-\mathrm{NH}_{2}$ group $\mathrm{p} K_{\mathrm{a}}$ value would have led to an erroneous $\Delta \mathrm{p} K_{\mathrm{a}}$, since the hydrogen/proton donating and accepting groups in many known SMT multicomponent structures do not directly involve that group. By taking account of the actual interacting groups, the distribution map of ionization state versus $\Delta \mathrm{p} K_{\mathrm{a}}$ is obtained (Figure 2.3, Table 2.3). Salts could form at $\Delta \mathrm{p} K_{\mathrm{a}}$ well below 0 , and cocrystals could effectively form at $\Delta \mathrm{p} K_{\mathrm{a}}$ about 3. A similar result was observed in fumaric acid multicomponent crystals recently, in which cocrystals distributed around $53 \%$ in $\Delta \mathrm{p} K_{\mathrm{a}}>0$ region and $47 \%$ in $\Delta \mathrm{p} K_{\mathrm{a}}<0$ region. ${ }^{44}$ Thus, the $\Delta \mathrm{p} K_{\mathrm{a}}$ rule cannot be reliably used to predict ionization state in SMT multicomponent crystals. Therefore, bond length analysis and infrared spectroscopy were applied to establish the ionization state of SMT-Acs.

\subsubsection{Bond length analysis}

Bond lengths often give clues to the complex's ionization state. Bond length diagrams containing different forms of SMT and Acs in known crystal structures are shown in Figure 2.4. For SMT-Acs, the SMT $\mathrm{C}_{1}-\mathrm{N}_{1}$ and $\mathrm{C}_{1}-\mathrm{N}_{2}$ bond lengths (1.366 
and $1.354 \AA$, respectively, Figure 2.4a). Thus, SMT-Acs falls into the SMT cation region, whereas Acs fall into the anionic group based on $\mathrm{C}_{2}-\mathrm{N}_{3}$ and $\mathrm{C}_{2}-\mathrm{O}_{1}$ bond lengths (1.352 and $1.256 \AA$, respectively, Figure $2.4 \mathrm{~b}) .{ }^{32,45}$ Thus, bond length analysis indicates salt formation for SMT-Acs.

\subsubsection{Fourier Transformation Infrared Spectroscopy}

Characteristic FTIR peaks of SMT and Acs-K can be observed in the spectrum of SMT-Acs (Figure 2.5). For example, the $\mathrm{C}=\mathrm{O}$ peak $\left(1652 \mathrm{~cm}^{-1}\right.$ in Acs-K) shows up at $1647 \mathrm{~cm}^{-1}$ in SMT-Acs, and the $\mathrm{N}-\mathrm{H}$ stretching frequency of SMT is shifted from $3440,3339 \mathrm{~cm}^{-1}$ to 3490 and $3389 \mathrm{~cm}^{-1}$ in SMT-Acs. Additionally, a $2636 \mathrm{~cm}^{-1}$ broad peak is observed in SMT-Acs, which corresponds to the $\mathrm{NH}^{+}$functional group stretching (between 2700 and $2400 \mathrm{~cm}^{-1}$ ), confirming that both SMT and Acs are in ionic state. ${ }^{32}$ Considering these data, complete proton transfer from Acs to SMT is confirmed for SMT-Acs.

\subsubsection{Solid-State Characterization}

\subsubsection{Phase Purity of the Bulk Powders}

Powder X-ray diffractogram (PXRD) of the bulk SMT-Acs powder matched the PXRD calculated from the single crystal structure (Figure 2.6). The experimental PXRD pattern (room temperature) was shifted to slightly smaller $2 \theta$ angles compared to the calculated pattern using structure solved at $100 \mathrm{~K}$ due to thermal expansion 
effect. $^{46,47}$ The good PXRD pattern match confirms the phase purity of the bulk powder.

\subsubsection{Thermal Analysis}

Both SMT and Acs exhibited single endotherms in their DSC traces (Figure 2.7a), with onset temperatures of $197{ }^{\circ} \mathrm{C}\left(\Delta \mathrm{H}_{\mathrm{f}}=144.7 \mathrm{~J} / \mathrm{g}\right)$ and $116^{\circ} \mathrm{C}\left(\Delta \mathrm{H}_{\mathrm{f}}=130.8 \mathrm{~J} / \mathrm{g}\right)$, respectively. Acs is volatile as significant weight loss occurred after melting (Figure 2.7c). SMT did not undergo detectable weight loss until about $20{ }^{\circ} \mathrm{C}$ above melting temperature (Figure 2.7c). An exothermal peak $198{ }^{\circ} \mathrm{C}$ was observed in SMT-Acs after the endothermal peak. These thermal events corresponded to bubbling at $198{ }^{\circ} \mathrm{C}$ without any sign of melting (Figure 2.7b), indicating dissociation of SMT and Ace and subsequent evaporation of Ace gave rise to the weight loss near $200{ }^{\circ} \mathrm{C}$ (Figure 2.7c). Importantly, SMT-Acs had negligible weight loss below $150{ }^{\circ} \mathrm{C}$, suggesting thermal stability acceptable for tablet development. ${ }^{48}$

\subsubsection{Moisture Sorption Behavior}

Low hygroscopicity is preferred as the moisture content could alter the flowability, tabletability, and cause stability issue. ${ }^{49-51}$ The Acs free acid takes up nearly $30 \%$ of water when RH increased from $70 \%$ to $95 \%$ (Figure 2.8). Thus, Acs is very hygroscopic according to the classification in the European Pharmacopeia. ${ }^{52}$ SMT is non-hygroscopic, since it only takes up negligible amount of water, $0.6 \%$, at $95 \% \mathrm{RH}$. Moisture uptake by SMT-Acs, $0.2 \%$ at $95 \% \mathrm{RH}$, is the lowest, which also supports its 
use in tablet manufacturing.

\subsubsection{Tabletability}

A tensile strength of $2 \mathrm{MPa}$ is considered sufficient for maintaining tablet integrity during normal handling of most materials. ${ }^{53}$ The tabletability of SMT-Acs was significantly better than SMT (Figure 2.9a), where tensile strength of SMT-Acs tablets was approximately two times that of SMT tablet at a given pressure despite similar particle sizes (Figure 2.10). Importantly, SMT-Acs tablet reached $2 \mathrm{MPa}$ tensile strength at about $150 \mathrm{MPa}$, whereas SMT could not reach $2 \mathrm{MPa}$ over the entire range of compaction pressure. Thus, the improved tabletability of SMT-Acs also supports its use in tablet manufacturing.

The higher tabletability can be attributed to either larger BA, higher BS, or both. ${ }^{54,55}$ To better understand the underlying mechanism of tabletability improvement, the plasticity of SMT and SMT-Acs was assessed, because more plastic materials can deform more easily to result in larger bonding area (BA). SMT-Acs is more plastic than SMT, since both the $P_{y}$ and 1/C values of SMT-Acs were significantly lower than those of SMT (Table 2.4). The greater plasticity explains the steeper decrease in tablet porosity of SMT-Acs with increasing pressure (Figure 2.9b). It is interesting to note that tablet porosity of SMT-Acs was higher than that of SMT tablets at pressure $<300 \mathrm{MPa}$, despite the similar particle sizes (Figure 2.10). Thus, the bonding area may not account for the higher tabletability of SMT-Acs despite its higher plasticity. However, the tensile strength extrapolated to zero porosity, which 
is a parameter for assessing the apparent bonding strength (BS), was comparable between SMT-Acs and SMT (Figure 2.9c). Thus, BS cannot explain the superior tabletabilty of SMT-Acs. Consequently, the larger BA is responsible for the better tabletability of SMT-Acs despite the larger tablet porosity below $300 \mathrm{MPa}$ compaction pressures (Figure 2.9b). This is possible only when the plasticity of SMT-Acs is significantly higher than SMT, which is supported by its significantly lower $\mathrm{P}_{\mathrm{y}}$ and 1/C (Table 2.4). ${ }^{55}$

\subsection{Structure-properties relationship}

The origin of the significantly greater plasticity of SMT-Acs than SMT can be understood by quantitatively examining their crystal structures using a computational tool kit. ${ }^{56}$ The most likely two-dimensional layers in SMT run along the $a b$ plane (Figure 2.11a). Neighboring molecules in this layer interact through $\mathrm{N}-\mathrm{H}^{\cdots} \mathrm{O}=\mathrm{S}$ $(2.947 \AA)$ and $\mathrm{N}-\mathrm{H}^{\cdots \cdots} \mathrm{N}(3.092 \AA)$ hydrogen bonds as well as strong $\pi-\pi$ interaction (3.393 Å) (Figure 2.11a). Adjacent layers are fortified through weaker hydrogen bonds of $\mathrm{C}-\mathrm{H}^{\cdots} \mathrm{O}=\mathrm{S}(3.331 \AA$ ) (Figure 2.11a). The energy framework of SMT (Figure 11b) suggested that $\left(\begin{array}{lll}0 & 0 & 1\end{array}\right)$ planes exhibit higher intralayer bonding energy $(-261.1 \mathrm{~kJ} / \mathrm{mol})$ than the interlayer bonding energy $(-80.6 \mathrm{~kJ} / \mathrm{mol})$, which meets the anisotropic energy requirement for slip planes. However, the molecular layers sliding along the $\left(\begin{array}{lll}0 & 0 & 1\end{array}\right)$ is hindered by the interdigitation between layers (negative interlayer distance of -1.80 ̊) (Figure 2.11a).

In comparison, the SMT-Acs exhibits a columnar structure running along the $a$ axis 
(Figure 2.11c). Within the columns, molecules are linked by $\mathrm{N}-\mathrm{H}^{\cdots} \mathrm{N}(2.796 \AA)$, $\mathrm{N}-\mathrm{H}^{\cdots} \mathrm{O}(2.627 \AA)$, and $\mathrm{N}-\mathrm{H}^{\cdots} \mathrm{O}=\mathrm{S}(3.011 \AA$ A $)$ hydrogen bonds. Each column interacts with four neighboring columns via $\mathrm{N}-\mathrm{H}^{\cdots} \mathrm{O}=\mathrm{S}(2.995 \AA)$ hydrogen bonds (Figure 2.11c). The intracolumn bonding energy $(-256.7 \mathrm{~kJ} / \mathrm{mol})$ is much higher than the intercolumn bonding energy $(-92.8 \mathrm{~kJ} / \mathrm{mol})$ (Figure 2.11d), suggesting energetically favored molecular movement through slippage of columns, when the crystal is stressed. ${ }^{6}$ Both $\left(\begin{array}{lll}0 & 1 & 2\end{array}\right)$ and $\left(\begin{array}{lll}0 & 0 & 1\end{array}\right)$ are possible slip planes in SMT-Acs based on energy framework alone. However, the $\left(\begin{array}{lll}0 & 1 & 2\end{array}\right)$ plane is likely the primary slip plane because of the lowest degree of interdigitation between adjacent layers (-0.22 $\AA$ ) based on the topology analysis. Therefore, the crystal structure of SMT-Acs supports its higher plasticity than SMT established by bulk powder compaction data (Table 2.4). ${ }^{54}$

\subsection{Conclusions}

A sweet 1:1 salt between sulfamethazine and acesulfame was obtained. Characterization of solid-state and compaction properties suggests suitability of SMT-Acs for tablet formulation and manufacturing. The better tabletability of SMT-Acs was attributed to its higher plasticity, which in turn is explained by the favorable crystal structure, featuring facile slip planes. 
Table 2.1 Crystallographic data for the SMT-Acs crystal.

\begin{tabular}{ll}
\hline Name & SMT-Acs \\
\hline Formula & $\mathrm{C}_{16} \mathrm{H}_{19} \mathrm{~N}_{5} \mathrm{O}_{6} \mathrm{~S}_{2}$ \\
Formula weight & 441.48 \\
Temperature / K & $100(2)$ \\
Crystal system & Monoclinic \\
Space group & $\mathrm{P} 2{ }_{1} / \mathrm{n}$ \\
$a, \AA$ & $8.3209(2)$ \\
$b, \AA$ & $10.8674(3)$ \\
$c, \AA$ & $21.7899(5)$ \\
a, deg & 90 \\
b, deg & $99.9810(10)$ \\
g, deg & 90 \\
Volume, $\AA^{3}$ & $1940.56(8)$ \\
$Z$ & \\
$D c /$ g.cm & \\
$F(000)$ & 1.511 \\
$G O F$ & 920 \\
$R 1[I>2 \operatorname{sigma}(I)]$ & 0.0371 \\
$w R 2[I>2 \operatorname{sigma}(I)]$ & 0.0909 \\
\hline & \\
\hline
\end{tabular}


Table 2.2 Hydrogen bonds in SMT-Acs crystal.

\begin{tabular}{|c|c|c|c|c|c|}
\hline D-H...A & D-H (Å) & H..A (̊̊) & D..A (Å) & D-H...A (deg) & Symmetry codes \\
\hline C1-H1C...O1 & 0.980 & 2.643 & 3.593 & 163.23 & $-x+1,-y+2,-z+1$ \\
\hline N3-H3A...N1 & 0.881 & 1.916 & 2.796 & 175.99 & \\
\hline N2-H2B...O5 & 0.884 & 2.334 & 2.995 & 131.56 & $-x+3 / 2, y-1 / 2,-z+3 / 2$ \\
\hline N2-H2A...O6 & 0.833 & 2.204 & 3.011 & 163.05 & $\mathrm{x}+1, \mathrm{y}, \mathrm{z}$ \\
\hline N5-H5...O4 & 0.947 & 1.683 & 2.627 & 174.10 & \\
\hline C9-H9...O1 & 0.956 & 2.609 & 3.562 & 174.88 & \\
\hline C10-H10...O6 & 0.944 & 2.588 & 3.344 & 137.34 & $\mathrm{x}+1, \mathrm{y}, \mathrm{z}$ \\
\hline C13-H13...O2 & 0.951 & 2.579 & 3.246 & 127.52 & $\mathrm{x}, \mathrm{y}-1, \mathrm{z}$ \\
\hline C15'-H15D...O6 & 0.980 & 2.640 & 3.420 & 136.72 & $-x+1 / 2, y-1 / 2,-z+3 / 2$ \\
\hline C15'-H15E...O2 & 0.980 & 2.466 & 3.353 & 150.36 & $\mathrm{x}, \mathrm{y}-1, \mathrm{z}$ \\
\hline
\end{tabular}


Table 2.3 Realistic interaction sites and corresponding $\Delta \mathrm{pK}_{\mathrm{a}}$ in multicomponent crystals of SMT

\begin{tabular}{|c|c|c|c|c|}
\hline coformer & $\begin{array}{c}\text { SMT } \\
\text { conformation } \\
\end{array}$ & $\begin{array}{l}\text { SMT interaction } \\
\text { site \& } \mathrm{pK}_{\mathrm{a}} \\
\end{array}$ & $\begin{array}{c}\text { Coformer } \\
\mathrm{pK}_{\mathrm{a}}\end{array}$ & $\Delta \mathrm{pK}_{\mathrm{a}}$ \\
\hline $\begin{array}{c}\text { 2,4-dihydroxybenzoic } \\
\text { acid }\end{array}$ & amidine & $\begin{array}{l}\text { pyrimidine }-\mathrm{N}- \\
\text { (base) },-0.97\end{array}$ & 3.11 & -4.08 \\
\hline 3,4-dichlorobenzoic acid & amidine & $\begin{array}{c}\text { pyrimidine }-\mathrm{N}- \\
\text { (base), }-0.97 \\
\end{array}$ & 3.6 & -4.57 \\
\hline sorbic acid & amidine & $\begin{array}{l}\text { pyrimidine }-\mathrm{N}- \\
\text { (base) },-0.97\end{array}$ & 4.76 & -5.73 \\
\hline $\begin{array}{l}\text { 1-hydroxy-2-naphthoic } \\
\text { acid } \\
\end{array}$ & amidine & $\begin{array}{c}\text { pyrimidine }-\mathrm{N}- \\
\text { (base), }-0.97 \\
\end{array}$ & 10.94 & -11.91 \\
\hline $\begin{array}{c}\text { benzene-1,2,4,5-tetracar } \\
\text { boxylic acid }\end{array}$ & amidine & $\begin{array}{l}\text { pyrimidine }-\mathrm{N}- \\
\text { (base) },-0.97\end{array}$ & 1.87 & -2.84 \\
\hline 2-hydroxybenzoic acid & amidine & $\begin{array}{c}\text { pyrimidine }-\mathrm{N}- \\
\text { (base), }-0.97 \\
\end{array}$ & 2.97 & -3.94 \\
\hline 2-nitrobenzoic acid & amidine & $\begin{array}{l}\text { pyrimidine }-\mathrm{N}- \\
\text { (base) },-0.97\end{array}$ & 2.16 & -3.13 \\
\hline 4-nitrobenzoic acid & amidine & $\begin{array}{l}\text { pyrimidine }-\mathrm{N}- \\
\text { (base) },-0.97\end{array}$ & 3.41 & -4.38 \\
\hline 2-aminobenzoic acid & amidine & $\begin{array}{l}\text { pyrimidine }-\mathrm{N}- \\
\text { (base) },-0.97\end{array}$ & 2.14 & -3.11 \\
\hline 4-aminobenzoic acid & amidine & $\begin{array}{c}\text { pyrimidine }-\mathrm{N}- \\
\text { (base), }-0.97\end{array}$ & 2.38 & -3.35 \\
\hline $\begin{array}{c}\text { 1,4-diazabicyclo[2.2.2]o } \\
\text { ctane }\end{array}$ & amidine & $\begin{array}{c}\text { sulfonamide } \\
\text {-NH- (acid), } \\
6.99\end{array}$ & 8.7 & 1.71 \\
\hline acetylsalicylic acid & amidine & $\begin{array}{l}\text { pyrimidine }-\mathrm{N}- \\
\text { (base) },-0.97\end{array}$ & 3.49 & -4.46 \\
\hline 4-aminosalicylic acid & amidine & $\begin{array}{l}\text { pyrimidine }-\mathrm{N}- \\
\text { (base) },-0.97\end{array}$ & 3.25 & -4.22 \\
\hline indole-2-carboxylic acid & amidine & $\begin{array}{l}\text { pyrimidine }-\mathrm{N}- \\
\text { (base) },-0.97\end{array}$ & 4.44 & -5.41 \\
\hline 2,4-dinitrobenzoic acid & amidine & $\begin{array}{l}\text { pyrimidine }-\mathrm{N}- \\
\text { (base), }-0.97\end{array}$ & 1.43 & -2.4 \\
\hline 4-chlorobenzoic acid & amidine & $\begin{array}{l}\text { pyrimidine }-\mathrm{N}- \\
\text { (base), }-0.97\end{array}$ & 3.98 & -4.95 \\
\hline $\begin{array}{c}\text { 4,4'-ethane-1,2-diyldipyr } \\
\text { idine }\end{array}$ & amidine & $\begin{array}{l}\text { pyrimidine }-\mathrm{N}- \\
\text { (base), }-0.97\end{array}$ & 6.13 & 7.1 \\
\hline niflumic acid & amidine & $\begin{array}{l}\text { pyrimidine }-\mathrm{N}- \\
\text { (base), }-0.97\end{array}$ & 1.88 & -2.85 \\
\hline
\end{tabular}




\begin{tabular}{|c|c|c|c|c|}
\hline flufenamic acid & amidine & $\begin{array}{l}\text { pyrimidine }-\mathrm{N}- \\
\text { (base), }-0.97\end{array}$ & 3.88 & -4.85 \\
\hline 4-hydroxybenzoic acid & imidine & $\begin{array}{c}\text { sulfonamide -N- } \\
\text { (base), } 7.01\end{array}$ & 4.54 & 2.47 \\
\hline benzamide & imidine & $\begin{array}{l}\text { sulfonamide -N- } \\
\text { (base), } 7.01\end{array}$ & -2 & -9.01 \\
\hline picolinamide & imidine & $\begin{array}{c}\text { sulfonamide -N- } \\
\text { (base), } 7.01\end{array}$ & -1.08 & -8.09 \\
\hline 4-hydroxybenzamide & imidine & $\begin{array}{l}\text { sulfonamide -N- } \\
\text { (base), } 7.01\end{array}$ & -3.01 & -10.02 \\
\hline $\begin{array}{c}\text { 3-hydroxy-2-naphthoic } \\
\text { acid }\end{array}$ & imidine & $\begin{array}{l}\text { sulfonamide -N- } \\
\text { (base), } 7.01\end{array}$ & 2.79 & 4.22 \\
\hline saccharine & imidine & $\begin{array}{l}\text { sulfonamide -N- } \\
\text { (base), } 7.01\end{array}$ & 1.31 & 5.7 \\
\hline theophylline & $\begin{array}{l}\text { Amidine \& } \\
\text { imidine }\end{array}$ & $\begin{array}{c}\text { sulfonamide } \\
\text {-NH- (acid), } \\
6.99 \& \\
\text { sulfonamide -N- } \\
\text { (base), } 7.01\end{array}$ & $\begin{array}{c}7.82 \text { (acid) } \\
\& \quad-0.78 \\
\text { (base) }\end{array}$ & $\begin{array}{l}-0.81 \& \\
-7.77\end{array}$ \\
\hline 4-aminopyridine & anion & $\begin{array}{c}\text { sulfonamide } \\
\text {-NH- (acid), } \\
6.99\end{array}$ & 8.95 & 1.96 \\
\hline piperazine & anion & $\begin{array}{c}\text { sulfonamide } \\
\text {-NH- (acid), } \\
6.99\end{array}$ & 9.56 & 2.57 \\
\hline saccharin & cation & $\begin{array}{l}\text { pyrimidine }-\mathrm{N}- \\
\text { (base), }-0.97\end{array}$ & 1.31 & -2.28 \\
\hline 5-nitro-salicylic acid & cation & $\begin{array}{l}\text { pyrimidine }-\mathrm{N}- \\
\text { (base), }-0.97\end{array}$ & 2.2 & -3.17 \\
\hline picric acid & cation & $\begin{array}{l}\text { pyrimidine }-\mathrm{N}- \\
\text { (base), }-0.97\end{array}$ & 0.42 & -1.39 \\
\hline 3,5-dinitrosalicylic & cation & $\begin{array}{l}\text { pyrimidine }-\mathrm{N}- \\
\text { (base), }-0.97\end{array}$ & 1.53 & -2.5 \\
\hline acesulfame & cation & $\begin{array}{l}\text { pyrimidine }-\mathrm{N}- \\
\text { (base), }-0.97\end{array}$ & 2 & -2.97 \\
\hline
\end{tabular}


Table 2.4 Plasticity parameters of SMT and SMT-Acs from in-die Heckel analysis and out-of-die KL analysis.

\begin{tabular}{ccccc}
\hline & \multicolumn{2}{c}{ SMT } & \multicolumn{2}{c}{ SMT-Acs } \\
\hline $\boldsymbol{P}_{\boldsymbol{y}}(\mathbf{M P a})$ & $77.1 \pm 1.2$ & $\left(\mathrm{R}^{2}=0.99\right)$ & $57.2 \pm 3.3$ & $\left(\mathrm{R}^{2}=0.98\right)$ \\
$\boldsymbol{1} / \boldsymbol{C}(\mathbf{M P a})$ & $3345 \pm 422$ & $\left(\mathrm{R}^{2}=0.98\right)$ & $818 \pm 101$ & $\left(\mathrm{R}^{2}=0.98\right)$ \\
\hline
\end{tabular}


(a)

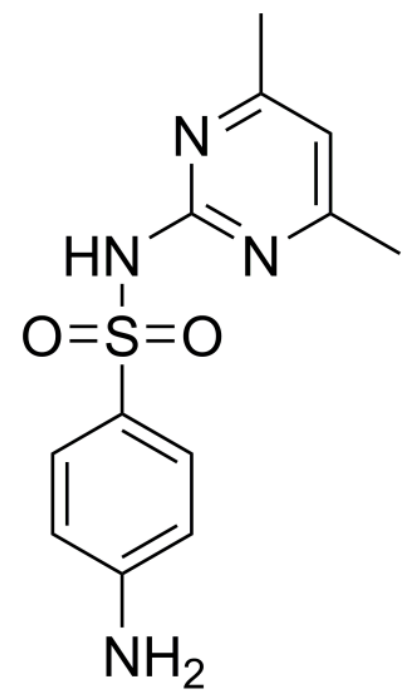

(b)<smiles>CC1=CC(=O)NS(=O)(=O)O1</smiles>

Figure 2.1 Molecular structure of (a) sulfamethazine (b) acesulfame. 
(a)

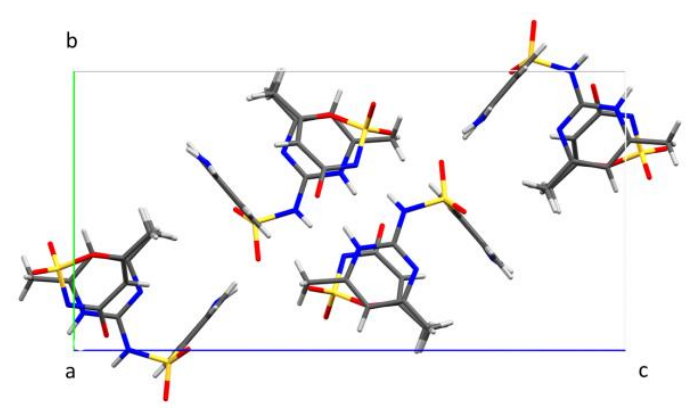

(c)

(b)

(d)
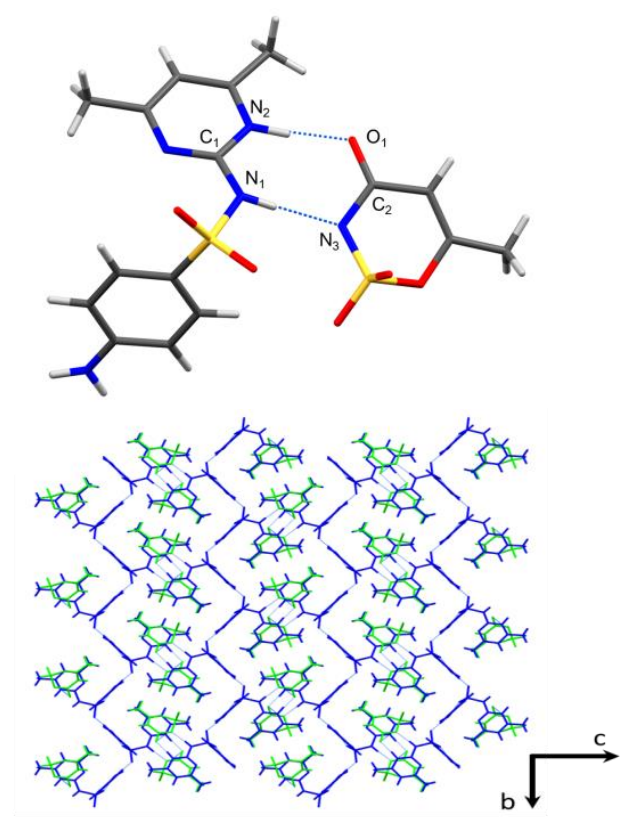

Figure 2.2 Crystal structure of SMT-Acs: (a) unit cell viewed along $a$-axis, (b) asymmetric unit, (c) $\mathrm{SMT}^{+}$cations formed a chain along the $b$-axis, (d) three-dimensional packing diagram. 


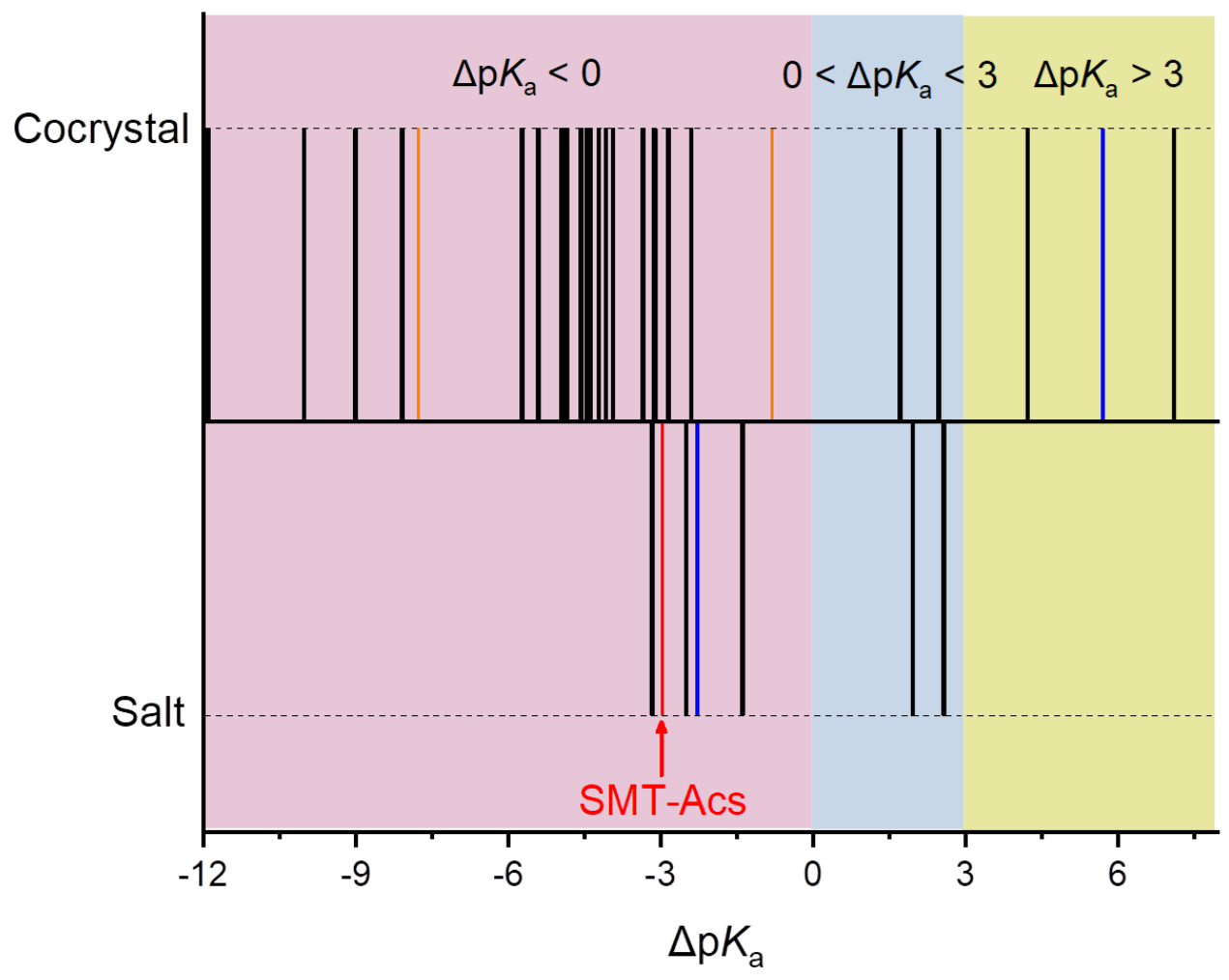

Figure 2.3 Ionization state distribution of SMT multicomponent crystals versus $\Delta \mathrm{p} K_{\mathrm{a}}$ between interacting groups. Saccharin (blue line) forms both cocrystal and salt with SMT, while theophylline (orange line) forms cocrystal with amidine and imidine SMT simultaneously. 
(a)

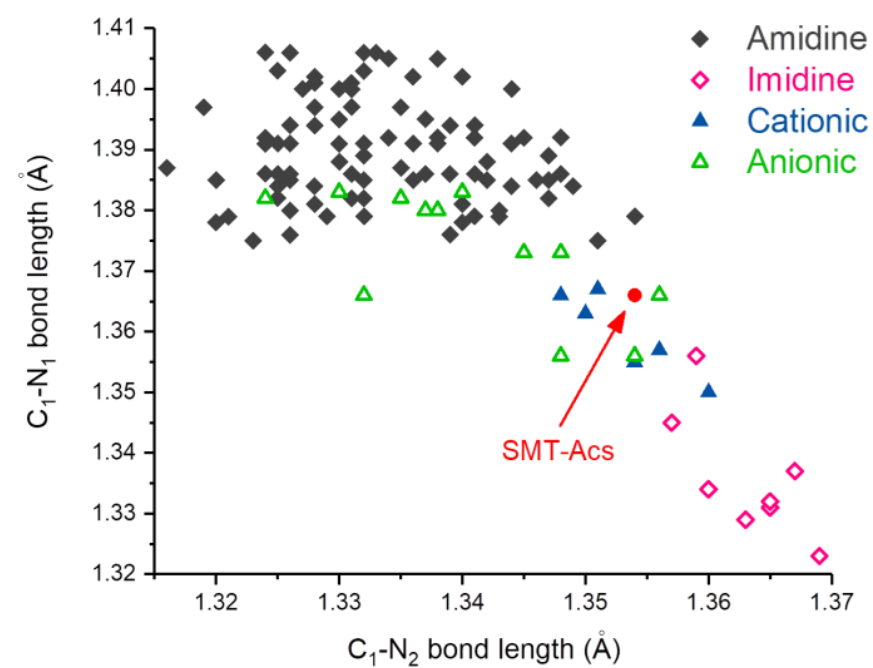

(b)

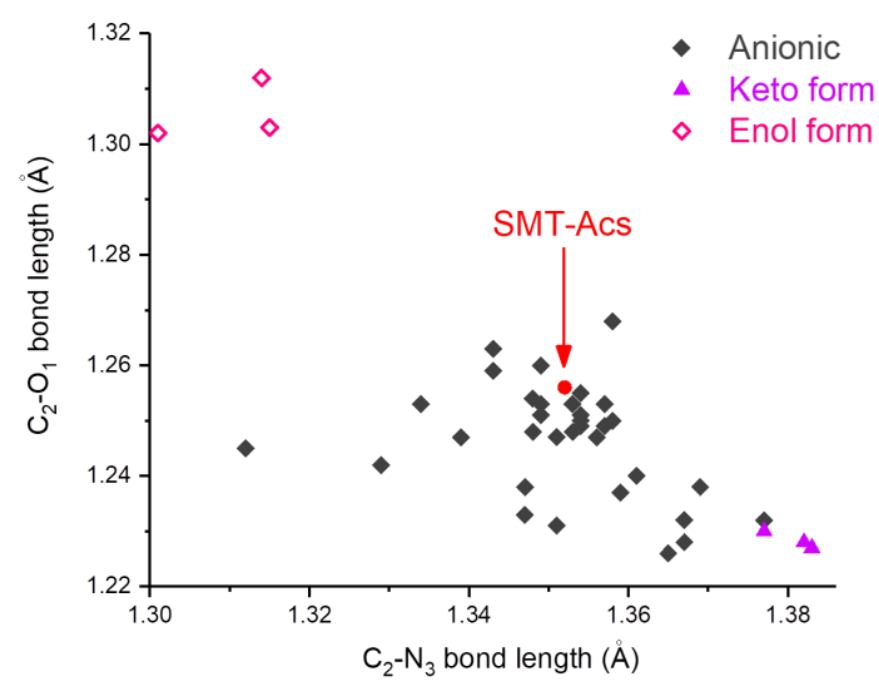

Figure 2.4 Bond length distributions of (a) $\mathrm{C}_{1}-\mathrm{N}_{2}$ vs. $\mathrm{C}_{1}-\mathrm{N}_{1}$ for SMT in crystal structures containing SMT, (b) $\mathrm{C}_{2}-\mathrm{N}_{3} v s . \mathrm{C}_{2}-\mathrm{O}_{1}$ for Acs in known crystal structures containing Acs 


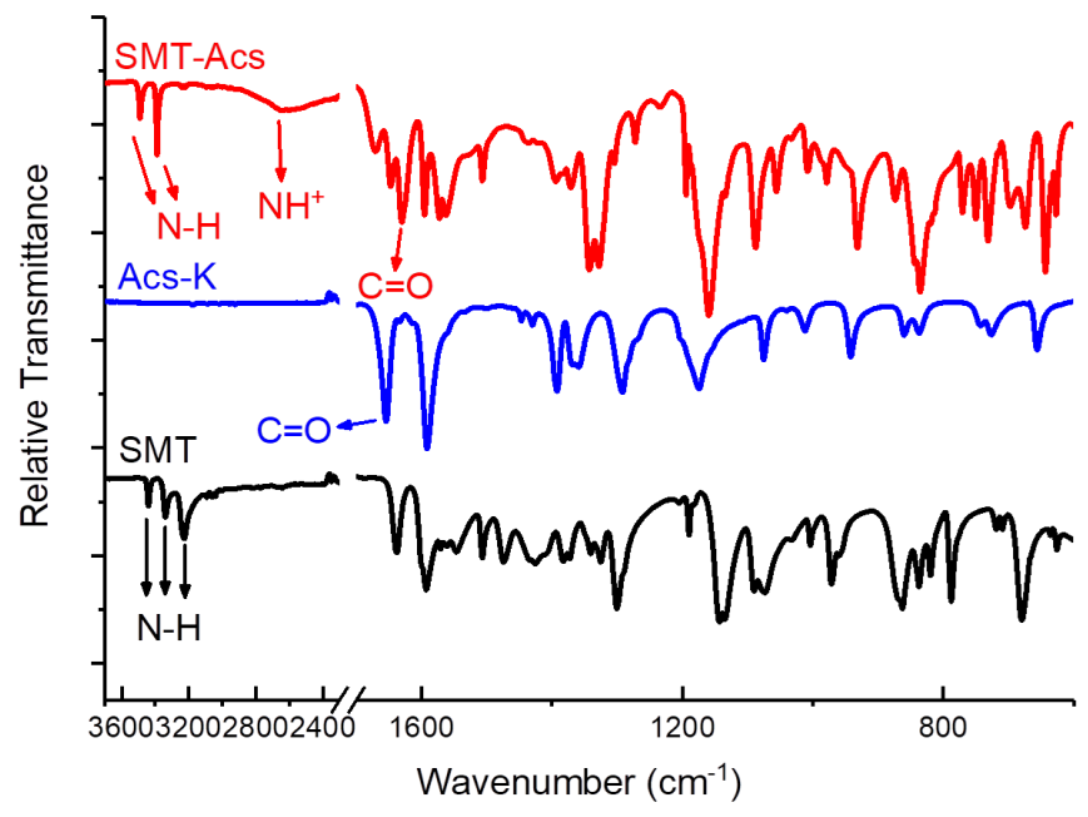

Figure 2.5 IR spectra for SMT, Acs-K, and SMT-Acs. The $2636 \mathrm{~cm}^{-1}$ broad peak corresponds to $\mathrm{NH}^{+}$stretching. 


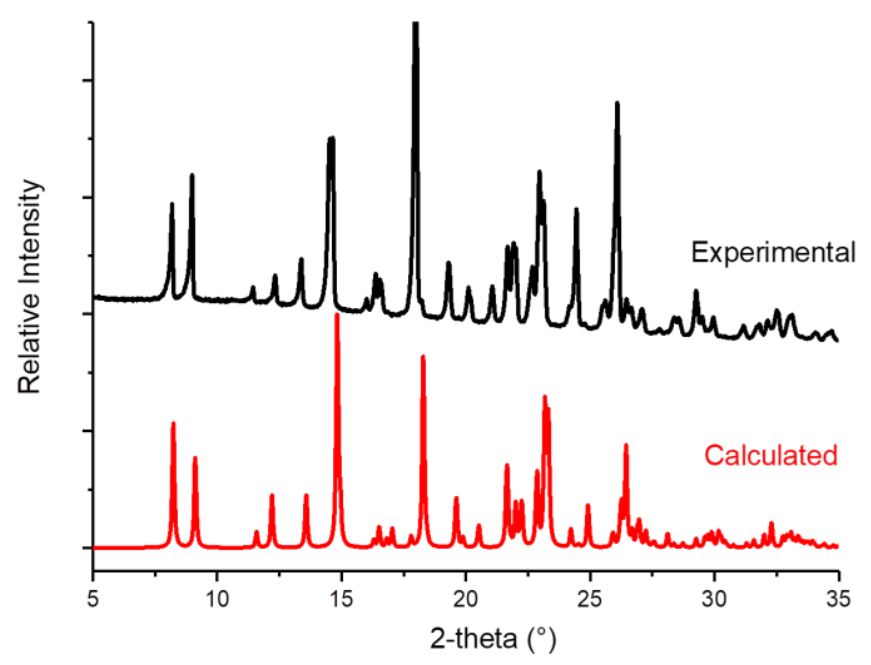

Figure 2.6 Calculated and experimental PXRD patterns of SMT-Acs 
(a)

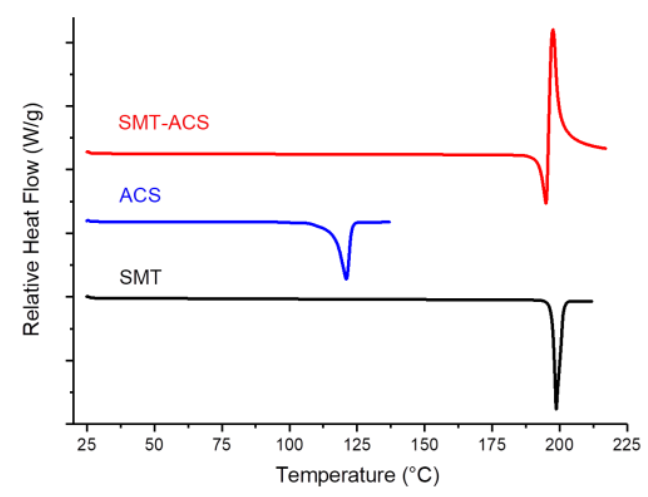

(c)

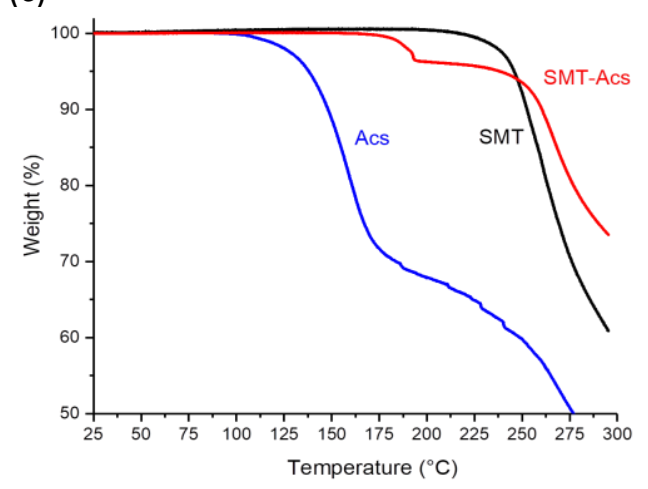

(b)

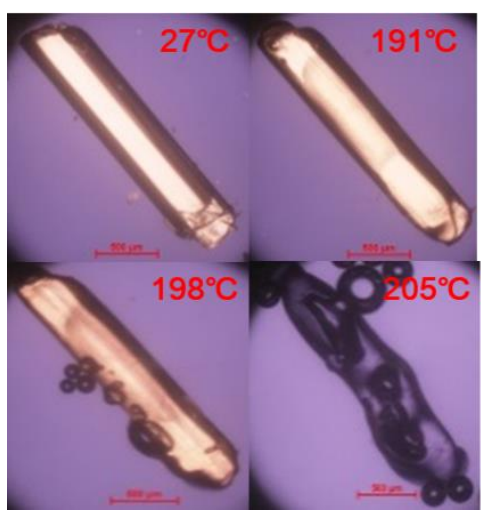

Figure 2.7 Thermal analysis of SMT, Acs, and SMT-Acs: (a) DSC, (b) HSM, and (c) TGA 


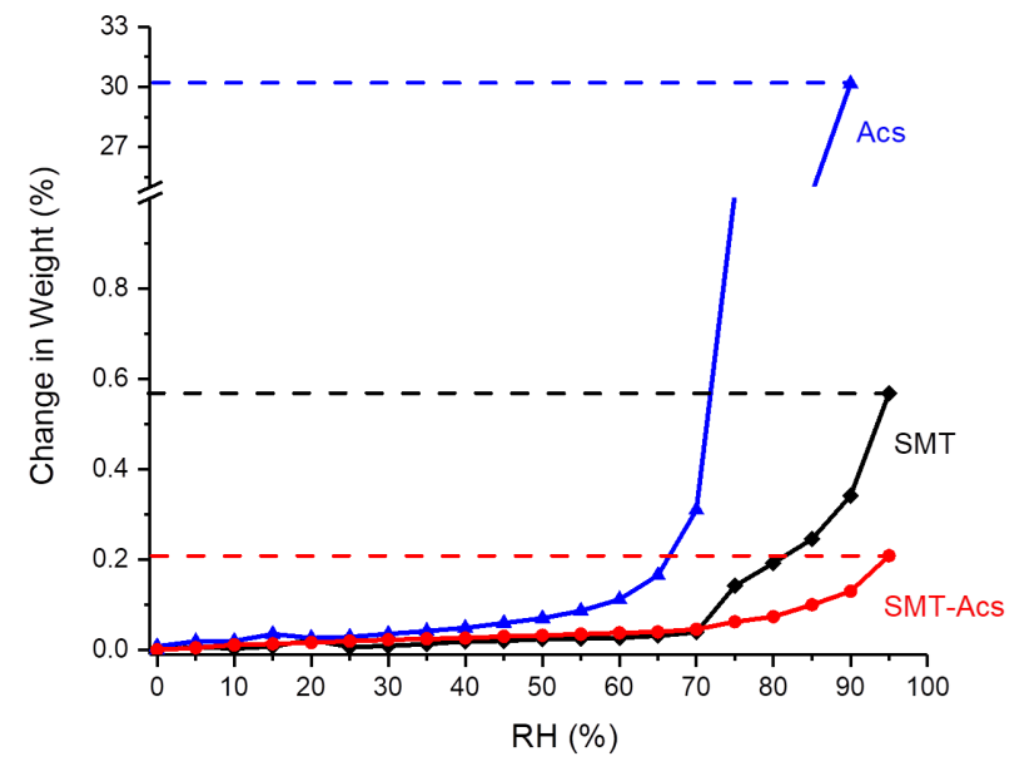

Figure 2.8 Moisture sorption curves of SMT, Acs and SMT-Acs. 
(a)

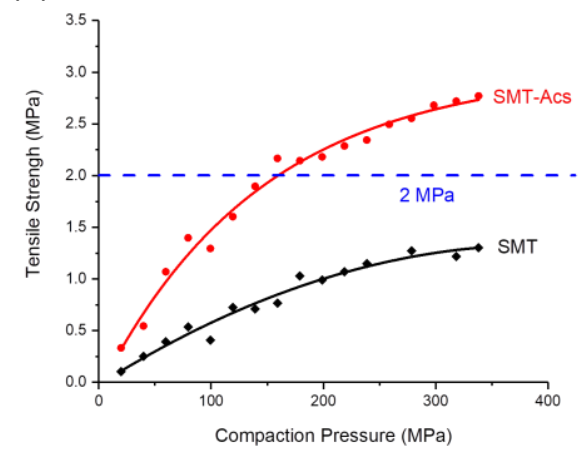

(c)

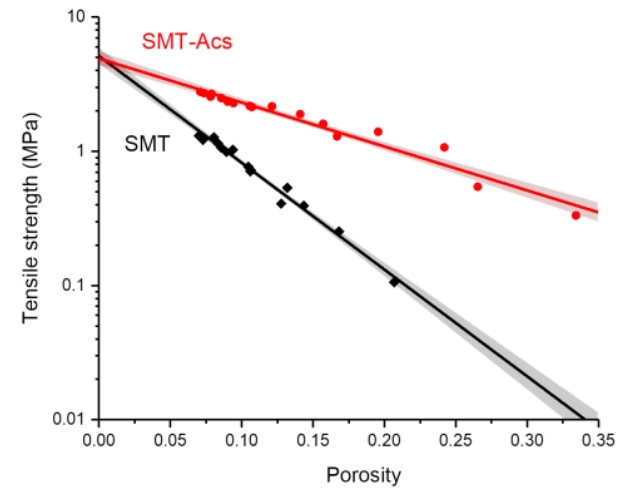

(b)

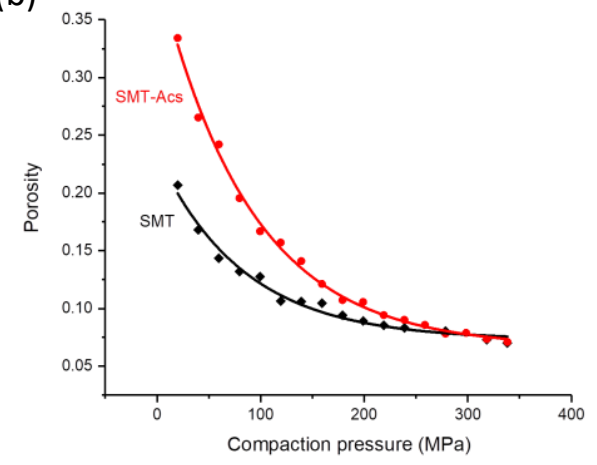

Figure 2.9 (a) Tabletability (b) compressibility, and (c) compactability profiles of SMT and SMT-Acs, where the shaded bands indicate $90 \%$ confidence interval. 
(a)

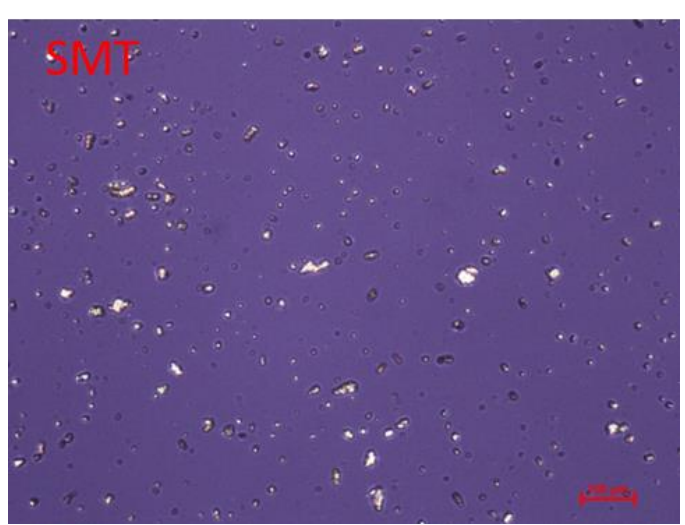

(b)

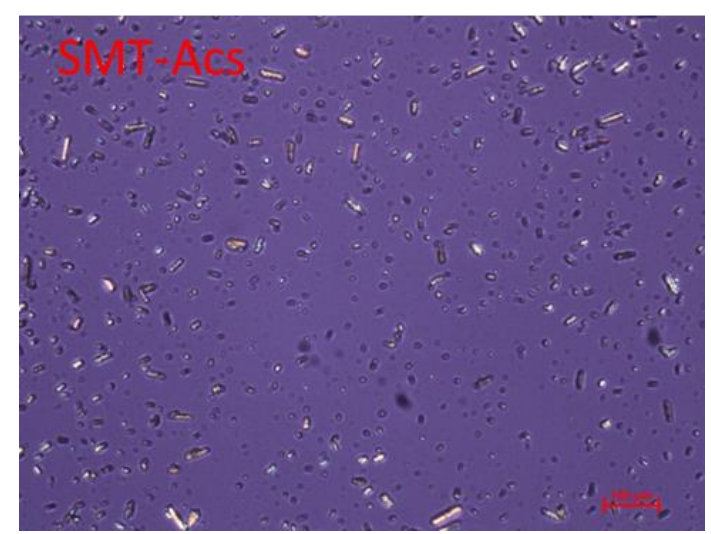

Figure 2.10 Particle size of (a) SMT and (b) SMT-Acs. 

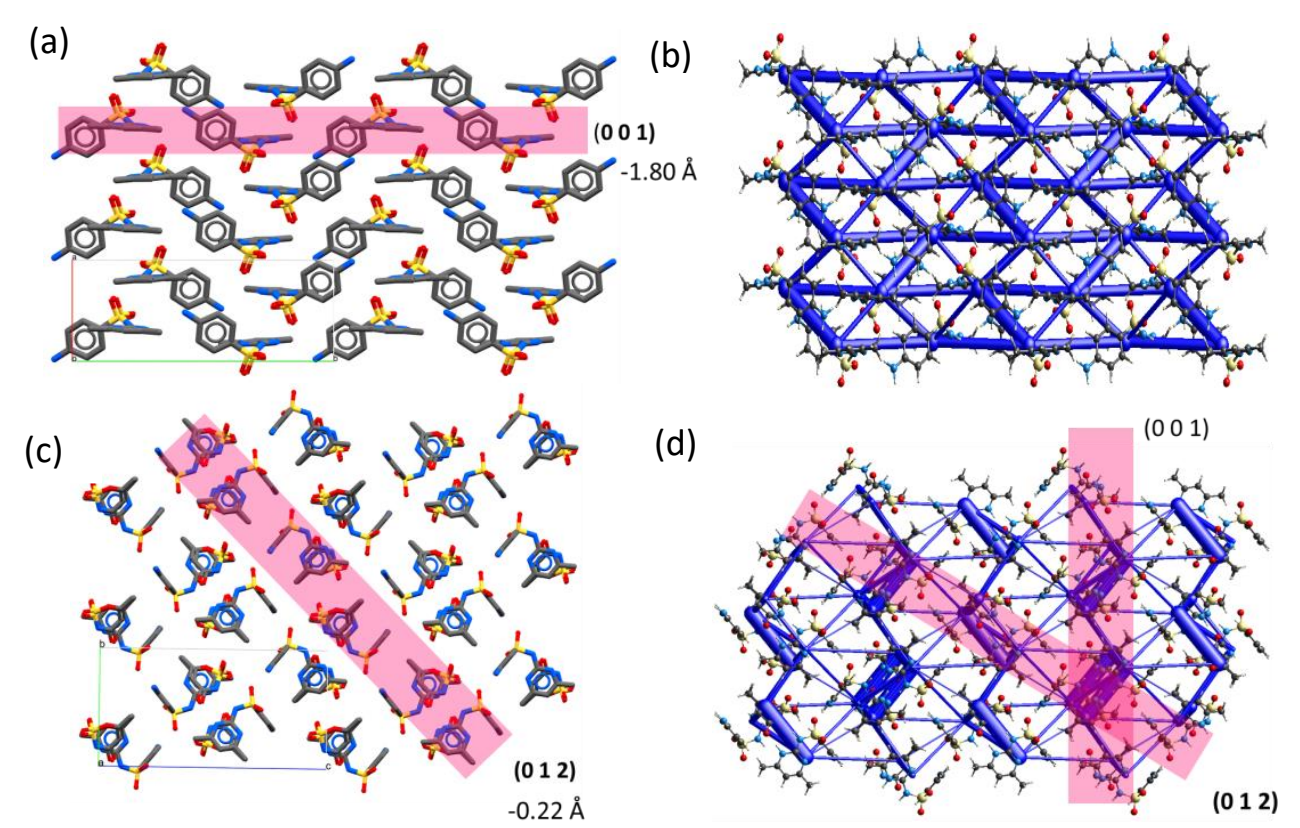

Figure 2.11 Crystal packing patterns (left) and corresponding energy framework (right) for SMT (a, b) and SMT-Acs salt $(\mathrm{c}, \mathrm{d})$ viewed along $c$ axis. The thickness of each cylinder (in blue) represents the relative strength of interaction. 


\section{CHAPTER 3.}

\section{RESEARCH SUMMARY AND FUTURE WORK}




\section{Research Summary}

A sweet 1:1 salt between sulfamethazine and acesulfame, SMT-Acs, was successfully prepared and characterized. The solid-state and compaction properties of SMT-Acs suggests its suitability for tablet formulation and manufacturing. The better tabletability of SMT-Acs was attributed to its higher plasticity, which in turn is explained by the presence of facile slip planes in the crystal structure that favors plastic deformation.

\section{Future Work}

The thermal behavior of SMT-Acs captured by DSC and HSM are consistent. We also demonstrated the thermal stability of SMT-Acs from the TGA data. However, the nature of the thermal events between 190 and $200{ }^{\circ} \mathrm{C}$ remains elusive. Thus, further investigations are needed to fully understand the thermal properties of SMT-Acs. DSC experiments at different heating rates and variable temperature XRD may be of help to elucidate these observations. In addition, additional confirmation of the sweetness of SMT-Acs by either a taste panel or E - tongue test is needed. 


\section{REFERENCE}

\section{Chapter. 1}

(1) Kottke, M. J.; Rudnic, E. M., Tablet Dosage Forms. In Modern Pharmaceutics, CRC Press: 2002; pp 458-532.

(2) Davies, P., Oral Solid Dosage Forms. In Pharmaceutical Preformulation and Formulation, CRC Press: New York, 2015; pp 391-470.

(3) Allen, L.; Ansel, H. C., Ansel's Pharmaceutical Dosage Forms and Drug Delivery Systems. ed.; Lippincott Williams \& Wilkins: 2013.

(4) Jones, D. S., Fasttrack Pharmaceutics Dosage Form and Design. ed.; Pharmaceutical Press: 2016.

(5) Yu, L. X., Pharmaceutical Quality by Design: Product and Process Development, Understanding, and Control. Pharmaceutical Research 2008, 25, 781-791.

(6) Desiraju, G. R., Crystal Engineering: The Design of Organic Solids. ed.; Elsevier: New York, 1989.

(7) Desiraju, G. R., Crystal Engineering: A Holistic View. Angew. Chem., Int. Ed.. 2007, 46, 8342-8356.

(8) Tiekink, E. R. T.; Vittal, J. J., Frontiers in Crystal Engineering. ed.; Wiley Online Library: 2006.

(9) Schultheiss, N.; Newman, A., Pharmaceutical Cocrystals and Their Physicochemical Properties. Crystal Growth \& Design 2009, 9, 2950-2967.

(10)Reddy, C. M.; Rama Krishna, G.; Ghosh, S., Mechanical Properties of Molecular Crystals-Applications to Crystal Engineering. CrystEngComm 2010, 12, 2296-2314. (11) Sun, C. C.; Hou, H., Improving Mechanical Properties of Caffeine and Methyl Gallate Crystals by Cocrystallization. Crystal Growth \& Design 2008, 8, 1575-1579.

(12)Chattoraj, S.; Shi, L.; Sun, C. C., Understanding the Relationship between Crystal Structure, Plasticity and Compaction Behaviour of Theophylline, Methyl Gallate, and Their 1 : 1 Co-Crystal. CrystEngComm 2010, 12, 2466-2472.

(13)Perumalla, S. R.; Shi, L.; Sun, C. C., Ionized Form of Acetaminophen with Improved Compaction Properties. CrystEng Comm 2012, 14, 2389-2390.

(14)Sun, C.; Grant, D. J. W., Influence of Crystal Structure on the Tableting Properties of Sulfamerazine Polymorphs. Pharmaceutical research 2001, 18, 274-280.

(15)Sun, C. C.; Grant, D. J. W., Improved Tableting Properties of P-Hydroxybenzoic Acid by Water of Crystallization: A Molecular Insight. Pharmaceutical research 2004, 21, 382-386.

(16)Chen, H.; Wang, C.; Sun, C. C., Profoundly Improved Plasticity and Tabletability of Griseofulvin by in Situ Solvation and Desolvation During Spherical Crystallization. 
Crystal Growth \& Design 2019, 19, 2350-2357.

(17)Wang, C.; Sun, C. C., Identifying Slip Planes in Organic Polymorphs by Combined Energy Framework Calculations and Topology Analysis. Crystal Growth \& Design 2018, 18, 1909-1916.

(18)Wang, C.; Sun, C. C., Computational Techniques for Predicting Mechanical Properties of Organic Crystals: A Systematic Evaluation. Molecular Pharmaceutics 2019, 16, 1732-1741.

(19)Wood, J. R., Tablet Manufacture: Its History, Pharmacy and Practice. ed.; JB Lippincott Company: 1906.

(20)Patel, S.; Kaushal, A. M.; Bansal, A. K., Compression Physics in the Formulation Development of Tablets. Critical Reviews ${ }^{\mathrm{TM}}$ in Therapeutic Drug Carrier Systems 2006, 23.

(21)Sun, C. C., Decoding Powder Tabletability: Roles of Particle Adhesion and Plasticity. Journal of Adhesion Science and Technology 2011, 25, 483-499.

(22)Kuentz, M.; Leuenberger, H., A New Theoretical Approach to Tablet Strength of a Binary Mixture Consisting of a Well and a Poorly Compactable Substance. European journal of pharmaceutics and biopharmaceutics 2000, 49, 151-159.

(23)Hiestand, E. N., Mechanical Properties of Compacts and Particles That Control Tableting Success. Journal of pharmaceutical sciences 1997, 86, 985-990.

(24)Jain, S., Mechanical Properties of Powders for Compaction and Tableting: An Overview. Pharmaceutical Science \& Technology Today 1999, 2, 20-31.

(25)Endicott, C. J.; Lowenthal, W.; Gross, H. M., New Instrument and Method for Evaluating Tablet Fracture Resistance. Journal of pharmaceutical sciences 1961, 50, 343-346.

(26) Aulton, M. E.; Tebby, H. G.; White, P. J. P., Indentation Hardness Testing of Tablets. Journal of Pharmacy and Pharmacology 1974, 26, 59P-60P.

(27)Shafer, E. G. E.; Wollish, E. G.; Engel, C. E., The „Roche” $\square$ Friabilator. Journal of the American Pharmaceutical Association 1956, 45, 114-116.

(28)Becker, W. E., Pharmaceutical Tableting Method. In ed.; Google Patents: 1989.

(29)Fell, J. T.; Newton, J. M., Determination of Tablet Strength by the Diametral-Compression Test. Journal of Pharmaceutical Sciences 1970, 59, 688-691. (30)Shah, A. C.; Mlodozeniec, A. R., Mechanism of Surface Lubrication: Influence of Duration of Lubricant-Excipient Mixing on Processing Characteristics of Powders Properties of Compressed Tablets. Journal of pharmaceutical sciences 1977, 66, 1377-1382.

(31)Amidon, G. E.; Houghton, M. E., The Effect of Moisture on the Mechanical and Powder Flow Properties of Microcrystalline Cellulose. Pharmaceutical research 1995, 12, 923-929.

(32)Gupta, A.; Peck, G. E.; Miller, R. W.; Morris, K. R., Real-Time near-Infrared Monitoring of Content Uniformity, Moisture Content, Compact Density, Tensile Strength, and Young's Modulus of Roller Compacted Powder Blends. Journal of pharmaceutical sciences 2005, 94, 1589-1597.

(33)Sun, C. C., Mechanism of Moisture Induced Variations in True Density and Compaction Properties of Microcrystalline Cellulose. International journal of 
pharmaceutics 2008, 346, 93-101.

(34)Ibrahim, H. G.; Pisano, F.; Bruno, A., Polymorphism of Phenylbutazone: Properties and Compressional Behavior of Crystals. Journal of pharmaceutical sciences 1977, 66, 669-673.

(35)Burger, A.; Henck, J. O.; Hetz, S.; Rollinger, J. M.; Weissnicht, A. A.; Stöttner, H., Energy/Temperature Diagram and Compression Behavior of the Polymorphs of DMannitol. Journal of pharmaceutical sciences 2000, 89, 457-468.

(36)Hersey, J. A.; Bayraktar, G.; Shotton, E., The Effect of Particle Size on the Strength of Sodium Chloride Tablets. The Journal of pharmacy and pharmacology 1967, 19, Suppl-24S.

(37)Nicklasson, H.; Podczeckb, F., Evaluation of the Role of Pores During Strength Testing in Compacts Made from Different Particle Size Fractions of Sucrose. Chemical and pharmaceutical bulletin 2007, 55, 29-33.

(38)Fu, X.; Li, J.; Wang, L.; Wu, B.; Xu, X.; Deng, Z.; Zhang, H., Pharmaceutical Crystalline Complexes of Sulfamethazine with Saccharin: Same Interaction Site but Different Ionization States. RSC Advances 2016, 6, 26474-26478.

(39)Berry, D. J.; Steed, J. W., Pharmaceutical Cocrystals, Salts and Multicomponent Systems; Intermolecular Interactions and Property Based Design. Advanced drug delivery reviews 2017, 117, 3-24.

(40)Thakuria, R.; Nangia, A., Highly Soluble Olanzapinium Maleate Crystalline Salts. CrystEngComm 2011, 13, 1759-1764.

(41)Kong, M.; Fu, X.; Li, J.; Li, J.; Chen, M.; Deng, Z.; Zhang, H., Sweet Pharmaceutical Salts of Stanozolol with Enhanced Solubility and Physical Stability. CrystEngComm 2016, 18, 8739-8746.

(42)Administration, U. S. F. a. D., Regulatory Classification of Pharmaceutical Co-Crystals Guidance for Industry. In ed.; 2018.

(43)Childs, S. L.; Stahly, G. P.; Park, A., The Salt- Cocrystal Continuum: The Influence of Crystal Structure on Ionization State. Molecular pharmaceutics 2007, 4, 323-338.

(44)Sun, C. C., Cocrystallization for Successful Drug Delivery. Expert opinion on drug delivery 2013, 10, 201-213.

(45)Li, Z. J.; Abramov, Y.; Bordner, J.; Leonard, J.; Medek, A.; Trask, A. V., Solid-State Acid- Base Interactions in Complexes of Heterocyclic Bases with Dicarboxylic Acids: Crystallography, Hydrogen Bond Analysis, and 15n Nmr Spectroscopy. Journal of the American Chemical Society 2006, 128, 8199-8210.

(46)Steiner, T.; Majerz, I.; Wilson, C. C., First O- H- N Hydrogen Bond with a Centered Proton Obtained by Thermally Induced Proton Migration. Angewandte Chemie International Edition 2001, 40, 2651-2654.

(47)Haynes, D. A.; Jones, W.; Motherwell, W. D. S., Cocrystallisation of Succinic and Fumaric Acids with Lutidines: A Systematic Study. CrystEngComm 2006, 8, 830-840. (48)P. Heinrich Stahl, C. G. W., Handbook of Pharmaceutical Salts: Properties, Selection, and Use. ed.; Wiley-vch: 2002.

(49)Cruz-Cabeza, A. J., Acid-Base Crystalline Complexes and the Pka Rule. CrystEngComm 2012, 14, 6362-6365. 
(50)Sun, C. C., Materials Science Tetrahedron-a Useful Tool for Pharmaceutical Research and Development. Journal of Pharmaceutical Sciences 2009, 98, 1671-1687.

(51)Good, D. J.; Rodriguez-Hornedo, N., Solubility Advantage of Pharmaceutical Cocrystals. Crystal Growth and Design 2009, 9, 2252-2264.

(52)Gao, Y.; Zu, H.; Zhang, J., Enhanced Dissolution and Stability of Adefovir Dipivoxil by Cocrystal Formation. Journal of Pharmacy and Pharmacology 2011, 63, 483-490.

(53) Shiraki, K.; Takata, N.; Takano, R.; Hayashi, Y.; Terada, K., Dissolution Improvement and the Mechanism of the Improvement from Cocrystallization of Poorly Water-Soluble Compounds. Pharmaceutical research 2008, 25, 2581-2592.

(54)McNamara, D. P.; Childs, S. L.; Giordano, J.; Iarriccio, A.; Cassidy, J.; Shet, M. S.; Mannion, R.; O'Donnell, E.; Park, A., Use of a Glutaric Acid Cocrystal to Improve Oral Bioavailability of a Low Solubility Api. Pharmaceutical research 2006, 23, 1888-1897.

(55) Vangala, V. R.; Chow, P. S.; Tan, R. B. H., Characterization, Physicochemical and Photo-Stability of a Co-Crystal Involving an Antibiotic Drug, Nitrofurantoin, and 4-Hydroxybenzoic Acid. CrystEngComm 2011, 13, 759-762.

(56)Macgillivray, L. R.; Papaefstathiou, G. S.; Friščić, T.; Hamilton, T. D.; Bučar, D.-K.; Chu, Q.; Varshney, D. B.; Georgiev, I. G., Supramolecular Control of Reactivity in the Solid State: From Templates to Ladderanes to Metal- Organic Frameworks. Accounts of chemical research 2008, 41, 280-291.

(57)Braga, D.; Grepioni, F., Reactions between or within Molecular Crystals. Angewandte Chemie International Edition 2004, 43, 4002-4011.

(58)Karki, S.; Friščić, T.; Fabian, L.; Laity, P. R.; Day, G. M.; Jones, W., Improving Mechanical Properties of Crystalline Solids by Cocrystal Formation: New Compressible Forms of Paracetamol. Advanced materials 2009, 21, 3905-3909.

(59) Aitipamula, S.; Chow, P. S.; Tan, R. B. H., Dimorphs of a 1: 1 Cocrystal of Ethenzamide and Saccharin: Solid-State Grinding Methods Result in Metastable Polymorph. CrystEngComm 2009, 11, 889-895.

(60)Banerjee, R.; Bhatt, P. M.; Ravindra, N. V.; Desiraju, G. R., Saccharin Salts of Active Pharmaceutical Ingredients, Their Crystal Structures, and Increased Water Solubilities. Crystal growth \& design 2005, 5, 2299-2309.

(61)Bhatt, P. M.; Ravindra, N. V.; Banerjee, R.; Desiraju, G. R., Saccharin as a Salt Former. Enhanced Solubilities of Saccharinates of Active Pharmaceutical Ingredients. Chemical Communications 2005, 1073-1075.

(62)Joiris, E.; Martino, P. D.; Berneron, C.; Guyot-Hermann, A.-M.; Guyot, J.-C., Compression Behavior of Orthorhombic Paracetamol. Pharmaceutical Research 1998, $15,1122-1130$.

(63)Beyer, T.; Day, G. M.; Price, S. L., The Prediction, Morphology, and Mechanical Properties of the Polymorphs of Paracetamol. Journal of the American Chemical Society 2001, 123, 5086-5094.

(64)Turner, M. J.; Thomas, S. P.; Shi, M. W.; Jayatilaka, D.; Spackman, M. A., Energy Frameworks: Insights into Interaction Anisotropy and the Mechanical 
Properties of Molecular Crystals. Chemical Communications 2015, 51, 3735-3738.

\section{Chapter. 2}

(1) Desiraju, G. R., Crystal Engineering: The Design of Organic Solids. ed.; Elsevier: New York, 1989.

(2) Desiraju, G. R., Crystal Engineering: A Holistic View. Angew. Chem., Int. Ed.. 2007, 46, 8342-8356.

(3) Schultheiss, N.; Newman, A., Pharmaceutical Cocrystals and Their Physicochemical Properties. Crystal Growth \& Design 2009, 9, 2950-2967.

(4) Reddy, C. M.; Rama Krishna, G.; Ghosh, S., Mechanical Properties of Molecular Crystals-Applications to Crystal Engineering. CrystEngComm 2010, 12, 2296-2314.

(5) Sun, C. C.; Hou, H., Improving Mechanical Properties of Caffeine and Methyl Gallate Crystals by Cocrystallization. Crystal Growth \& Design 2008, 8, 1575-1579.

(6) Chattoraj, S.; Shi, L.; Sun, C. C., Understanding the Relationship between Crystal Structure, Plasticity and Compaction Behaviour of Theophylline, Methyl Gallate, and Their 1 : 1 Co-Crystal. CrystEng Comm 2010, 12, 2466-2472.

(7) Berry, D. J.; Steed, J. W., Pharmaceutical Cocrystals, Salts and Multicomponent Systems; Intermolecular Interactions and Property Based Design. Advanced Drug Delivery Reviews 2017, 117, 3-24.

(8) Thakuria, R.; Nangia, A., Highly Soluble Olanzapinium Maleate Crystalline Salts. CrystEngComm 2011, 13, 1759-1764.

(9) Kong, M.; Fu, X.; Li, J.; Li, J.; Chen, M.; Deng, Z.; Zhang, H., Sweet Pharmaceutical Salts of Stanozolol with Enhanced Solubility and Physical Stability. CrystEngComm 2016, 18, 8739-8746.

(10)Papich, M. G., Sulfamethazine. In Saunders Handbook of Veterinary Drugs (Fourth Edition), Papich, M. G., Ed. W.B. Saunders: St. Louis, 2016; pp 752-753.

(11) Ghosh, S.; Bag, P. P.; Reddy, C. M., Co-Crystals of Sulfamethazine with Some Carboxylic Acids and Amides: Co-Former Assisted Tautomerism in an Active Pharmaceutical Ingredient and Hydrogen Bond Competition Study. Crystal Growth \& Design 2011, 11, 3489-3503.

(12)Arman, H. D.; Tiekink, E. R. T., A Doubly Interpenetrated Layer Structure in the 1:1 Cocrystal Formed between Pyromellitic Acid and 4-Amino-N-(4,6-Dimethyl-2-Pyrimidinyl)Benzenesulfonamide. Journal of Chemical Crystallography 2013, 43, 134-137.

(13)Arman, H. D.; Kaulgud, T.; Tiekink, E. R. T., 4-Amino-N-(4,6-Dimethylpyrimidin-2-Yl)Benzenesulfonamide-1,4-Diazabicyclo[2.2. 2]Octane (2/1). Acta Crystallographica Section E 2013, 69, o1615.

(14)Caira, M. R., Molecular Complexes of Sulfonamides. 2.1:1 Complexes between Drug Molecules: Sulfadimidine-Acetylsalicylic Acid and Sulfadimidine-4-Aminosalicylic Acid. Journal of Crystallographic and Spectroscopic Research 1992, 22, 193-200.

(15)Caira, M. R., Molecular Complexes of Sulfonamides. Part 1. 1:1 Complexes 
[4-Amino-N-(4,6-Dimethyl-2-Pyrimidinyl)Benzenesulfonamide] and 2- and 4-Aminobenzoic Acids. Journal of Crystallographic and Spectroscopic Research 1991, 21, 641-648.

(16)Kumar, V.; Thaimattam, R.; Dutta, S.; Munshi, P.; Ramanan, A., Structural Landscape of Multicomponent Solids Based on Sulfa Drugs. CrystEngComm 2017, 19, 2914-2924.

(17)Lu, J.; Cruz-Cabeza, A. J.; Rohani, S.; Jennings, M. C., A 2:1 Sulfamethazine-Theophylline Cocrystal Exhibiting Two Tautomers of Sulfamethazine. Acta Crystallographica Section C 2011, 67, o306-o309.

(18)Lucaciu, R.; Ionescu, C.; Wildervanck, A.; Caira, M. R., Effect of Crystal Packing on H-Bond Parameters: X-Ray Structure of the Sulfadimidine.P-Chlorobenzoic Acid Co-Crystal. Analytical Sciences: X-ray Structure Analysis Online 2008, 24, x87-x88.

(19)Lynch, D. E.; Sandhu, P.; Parsons, S., 1 : 1 Molecular Complexes of 4-Amino-2-(4,6-Dimethylpyrimidin-2-Yl)Benzene-Sulfonamide (Sulfamethazine) with Indole-2-Carboxylic Acid and 2,4-Dinitrobenzoic Acid. Australian Journal of Chemistry 2000, 53, 383-387.

(20)Patel, U.; Haridas, M.; Singh, T. P., Structure of the 1:1 Complex between 4-Amino-N-(4,6-Dimethyl-2-Pyrimidinyl)Benzenesulfonamide (Sulfadimidine) and 2-Hydroxybenzoic Acid (Salicylic Acid). Acta Crystallographica Section C 1988, 44, 1264-1267.

(21) Smith

G.; Wermuth,

$\mathrm{U}$.

D., 4-Amino-N-(4,6-Dimethylpyrimidin-2-Yl)Benzenesulfonamide-4-Nitrobenzoic Acid (1/1). Acta Crystallographica Section E 2012, 68, o1649-o1650.

(22)Smith, G.; Wermuth, U. 4-Amino-N-(4,6-Dimethylpyrimidin-2-Y1)Benzenesulfonamide-2-Nitrobenzoic Acid (1/1). Acta Crystallographica Section E 2013, 69, o234.

(23) Tiekink Edward, R. T.; Arman Hadi, D.; Kaulgud, T., 1:1 Co-Crystals of Sulfadimidine with Three Bipyridine-Type Molecules: Persistence of $\mathrm{N}-\mathrm{H}$...N Hydrogen Bonded Supramolecular Chains. In Zeitschrift für Kristallographie Crystalline Materials, ed.; 2014; Vol. 229, p 394.

(24)Fu, X.; Li, J.; Wang, L.; Wu, B.; Xu, X.; Deng, Z.; Zhang, H., Pharmaceutical Crystalline Complexes of Sulfamethazine with Saccharin: Same Interaction Site but Different Ionization States. RSC Advances 2016, 6, 26474-26478.

(25)Smith, G.; Wermuth, U. 2-(4-Aminobenzenesulfonamido)-4,6-Dimethylpyrimidin-1-Ium

2-Carboxy-4,6-Dinitrophenolate. Acta Crystallographica Section E 2013, 69, o472.

(26)Smith, G.; Wermuth, U. D., Proton-Transfer Compounds with 4-Amino-N-(4,6-Dimethylpyrimidin-2-Yl)Benzenesulfonamide (Sulfamethazine): The Structures and Hydrogen Bonding in the Salts with 5-Nitrosalicylic Acid and Picric Acid. Acta Crystallographica Section C 2013, 69, 538-543.

(27)Papastephanou, C.; Frantz, M., Sulfamethazine. In Analytical Profiles of Drug Substances, Florey, K., Ed. Academic Press: 1978; Vol. 7, pp 401-422. 
(28)von Rymon Lipinski, G.-W., The New Intense Sweetener Acesulfame K. Food Chemistry 1985, 16, 259-269.

(29)Kroger, M.; Meister, K.; Kava, R., Low-Calorie Sweeteners and Other Sugar Substitutes: A Review of the Safety Issues. Comprehensive Reviews in Food Science and Food Safety 2006, 5, 35-47.

(30)Wang, L.; Luo, M.; Li, J.; Wang, J.; Zhang, H.; Deng, Z., Sweet Theophylline Cocrystal with Two Tautomers of Acesulfame. Crystal Growth \& Design 2015, 15, 2574-2578.

(31)Wang, C.; Perumalla, S. R.; Lu, R.; Fang, J.; Sun, C. C., Sweet Berberine. Crystal Growth \& Design 2016, 16, 933-939.

(32)Wang, C.; Perumalla, S. R.; Sun, C. C., Anion Exchange Reaction for Preparing Acesulfame Solid Forms. Crystal Growth \& Design 2018, 18, 4215-4219.

(33) Sheldrick, G., A Short History of Shelx. Acta Crystallographica Section A 2008, 64, 112-122.

(34)Sheldrick, G. M., Crystal Structure Refinement with Shelxl. Acta crystallographica. Section C, Structural chemistry 2015, 71, 3-8.

(35)Fell, J. T.; Newton, J. M., Determination of Tablet Strength by the Diametral-Compression Test. Journal of Pharmaceutical Sciences 1970, 59, 688-691. (36)Heckel, W., An Analysis of Powder Compaction Phenomena. Trans. Metall. Soc. AIME 1961, 221, p.671-675.

(37)Kuentz, M.; Leuenberger, H., Pressure Susceptibility of Polymer Tablets as a Critical Property: A Modified Heckel Equation. Journal of Pharmaceutical Sciences 1999, 88, 174-179.

(38)Paul, S.; Sun, C. C., The Suitability of Common Compressibility Equations for Characterizing Plasticity of Diverse Powders. International Journal of Pharmaceutics 2017, 532, 124-130.

(39)P. Heinrich Stahl, C. G. W., Handbook of Pharmaceutical Salts: Properties, Selection, and Use. ed.; Wiley-vch: 2002.

(40)Cruz-Cabeza, A. J., Acid-Base Crystalline Complexes and the Pka Rule. CrystEngComm 2012, 14, 6362-6365.

(41)Childs, S. L.; Stahly, G. P.; Park, A., The Salt-Cocrystal Continuum: The Influence of Crystal Structure on Ionization State. Molecular Pharmaceutics 2007, 4, 323-338.

(42)Administration, U. S. F. a. D., Regulatory Classification of Pharmaceutical Co-Crystals Guidance for Industry. In ed.; 2018.

(43)Groom, C. R.; Allen, F. H., The Cambridge Structural Database in Retrospect and Prospect. Angew. Chem., Int. Ed.. 2014, 53, 662-671.

(44)Chamorro Orué, A. I.; Boese, R.; Schauerte, C.; Merz, K., An Experimental and Theoretical Approach to Control Salt Vs Cocrystal Vs Hybrid Formation-Crystal Engineering of an E/Z-Butenedioic Acid/Phthalazine System. Crystal Growth \& Design 2019, 19, 1616-1620.

(45)Perumalla, S. R.; Wang, C.; Guo, Y.; Shi, L.; Sun, C. C., Robust Bulk Preparation and Characterization of Sulfamethazine and Saccharine Salt and Cocrystal Polymorphs. CrystEngComm 2018. 
(46)Sun, C. C., Thermal Expansion of Organic Crystals and Precision of Calculated Crystal Density: A Survey of Cambridge Crystal Database. Journal of Pharmaceutical Sciences 2007, 96, 1043-1052.

(47)Stephenson, G. A., Anisotropic Lattice Contraction in Pharmaceuticals: The Influence of Cryo-Crystallography on Calculated Powder Diffraction Patterns. Journal of Pharmaceutical Sciences 2006, 95, 821-827.

(48)Leane, M.; Pitt, K.; Reynolds, G., A Proposal for a Drug Product Manufacturing Classification System (Mcs) for Oral Solid Dosage Forms. Pharmaceutical Development and Technology 2015, 20, 12-21.

(49)Gupta, D.; Bhatia, D.; Dave, V.; Sutariya, V.; Varghese Gupta, S., Salts of Therapeutic Agents: Chemical, Physicochemical, and Biological Considerations. Molecules 2018, 23.

(50)Sun, C. C., Mechanism of Moisture Induced Variations in True Density and Compaction Properties of Microcrystalline Cellulose. International Journal of Pharmaceutics 2008, 346, 93-101.

(51)Sun, C. C., Quantifying Effects of Moisture Content on Flow Properties of Microcrystalline Cellulose Using a Ring Shear Tester. Powder Technology 2016, 289, 104-108.

(52)European Pharmacopoeia. In European Directorate for the Quality of Medicines (EDQM), ed.; Strasbong Cedex, 1997.

(53)Sun, C. C.; Hou, H.; Gao, P.; Ma, C.; Medina, C.; Alvarez, F. J., Development of a High Drug Load Tablet Formulation Based on Assessment of Powder Manufacturability: Moving Towards Quality by Design. Journal of Pharmaceutical Sciences 2009, 98, 239-247.

(54)Osei-Yeboah, F.; Chang, S.-Y.; Sun, C. C., A Critical Examination of the Phenomenon of Bonding Area - Bonding Strength Interplay in Powder Tableting. Pharmaceutical Research 2016, 33, 1126-1132.

(55)Sun, C. C., Decoding Powder Tabletability: Roles of Particle Adhesion and Plasticity. Journal of Adhesion Science and Technology 2011, 25, 483-499.

(56)Wang, C.; Sun, C. C., Computational Techniques for Predicting Mechanical Properties of Organic Crystals: A Systematic Evaluation. Molecular Pharmaceutics 2019, 16, 1732-1741. 